\title{
The Impact of the Cracks on the Harmonic Response of Stiffened Steel Plates
}

\section{Oguzhan Das ${ }^{a *}$ (iD, Can Gonenlib (i)}

a Department of Motor Vehicles and Transportation Technologies, Dokuz Eylul University, Izmir, Turkey, Email: oguzhan.das@deu.edu.tr

${ }^{b}$ Department of Machine Drawing and Construction, Ege University, Izmir, Turkey, Email: can.gonenli@ege.edu.tr

* Corresponding author

https://doi.org/10.1590/1679-78256790

\begin{abstract}
Stiffened plates are employed in various engineering structures including aerospace, civil, naval, etc. These structures may be subjected to harmonic loads. Therefore, it is essential to understand the harmonic response of a cracked stiffened structure. This study presents the effects of the crack location on the free vibration and harmonic response of the stiffened plates. For this purpose, horizontal and vertical cracks are modelled throughout the fixed from two-side structure. The analyses are performed via the Finite Element Method and the Mode Superposition technique. The natural frequencies and the displacement responses of the cracked and healthy structures are obtained and interpreted. It is concluded that a horizontal crack can decrease the third natural frequency by $60 \%$ as it is located in the center of the stiffened plate that is fixed from its nonstiffened edges. Thus, the displacement response of the stiffened structures is increased by $18 \%$ in the presence of the side horizontal or vertical cracks, which are located at the free ends of the stiffened structures no matter which boundary condition is considered.
\end{abstract}

\section{Keywords}

Harmonic response, free vibration, finite element method, stiffened plates, cracked structure

\section{Graphical abstract}

Modeling Cracked and Healthy Stiffened Structures
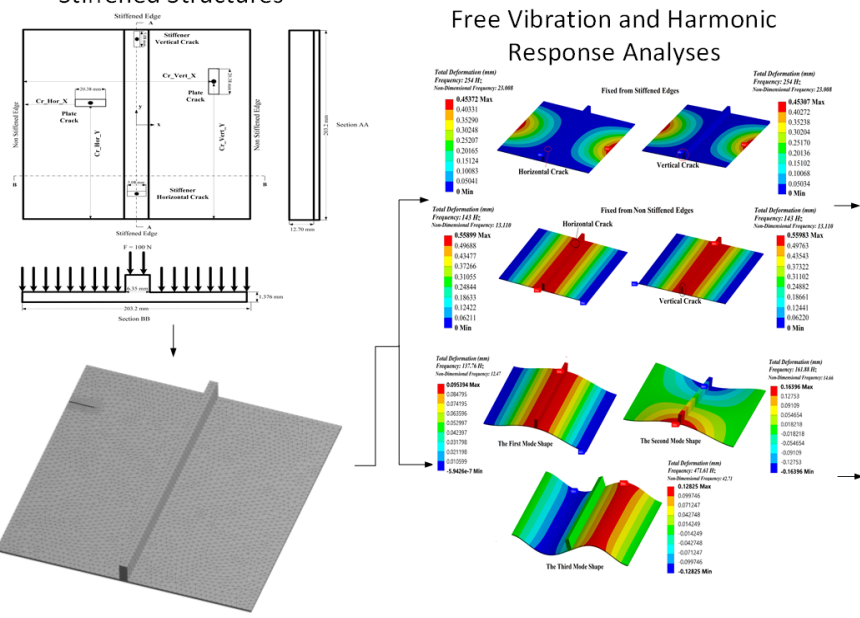

Impact of the Crack
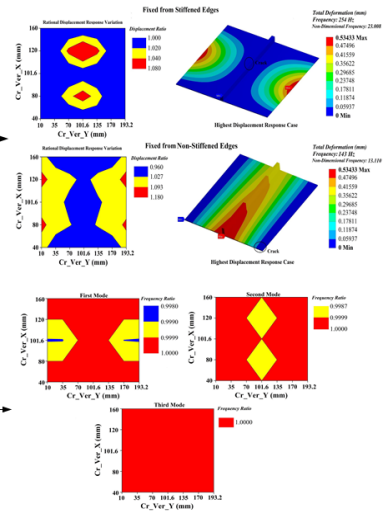


\section{NOMENCLATURE}

\section{Symbol Meaning Symbol Meaning}

$\{\delta\}$ Displacement Vector $\delta_{\text {healthy }}$ Displacement Response of Healthy Structure

$\left\{\delta_{\max }\right\}$ Maximum Displacement Vector $\delta_{\text {cracked }}$ Displacement Response of Cracked Structure

$[K]$ Stiffness Matrix $a$ Length of the Square Structure

[M] Mass Matrix $h$ Thickness of the Structure

[C] Damping Matrix $a_{\text {stiff }}$ Length of the Stiffener

$\{F\}$ Force Vector $h_{\text {stiff }}$ Thickness of the Stiffener

$\left\{F_{\max }\right\}$ Maximum Force Vector $E$ Modulus of Elasticity

$\varphi$ Phase Shift of the Applied Force $G$ Shear Modulus

$\psi$ Phase Shift of the Response $u$ Poisson's Ratio

$\omega$ Natural Frequency $\rho$ Density

$\omega_{d}$ Dimensionless Natural Frequency t Time

$\omega_{\text {healthy }}$ Dimensionless Natural Frequency of Healthy Structure $u, v, w$ Translations in $x, y$, and $z$ axis

$\omega_{\text {cracked }}$ Dimensionless Natural Frequency of Cracked Structure $\theta x, \theta y, \theta z$ Rotations in $x, y$, and $z$ axis

\section{INTRODUCTION}

Harmonic response analysis is an essential task to be performed during the designing phase of an engineering structure to understand the dynamic behavior of a structure in the presence of the harmonic load. Such a load may produce excessive vibrations on the structures that may generate stress, displacement, and noise at a high level, which is produced by excessive and frequent oscillations. The observability of the adverse effects of a harmonic load on a damaged structure would increase since damage reduces the integrity of a structure. Therefore, the characteristics of the damage (i.e., type, severity, location) should be investigated in terms of their effects on the harmonic response of a structure. Due to all aspects mentioned above, researchers have studied the vibrational characteristics of engineering structures in various ways. Some of those works have been briefly presented as follows.

Ramesha et al. (2015) investigated the modal and harmonic response analysis of a single-cylinder engine crankshaft in ANSYS Workbench. The first twelve modes of vibration have been extracted for free-free and ball bearing constrained boundary conditions to observe both the vibrational modes and displacement response of the crankshaft. Damnjanović et al. (2017) utilized the dynamic stiffness method based on the Higher-Order Shear Deformation Theory (HSDT) and First-Order Shear Deformation Theory (FSDT) to examine free vibration behaviors of stiffened and cracked plate assemblies. Yu et al. (2017) presented an ANSYS-based modal analysis of the ditch device to obtain natural frequencies and harmonic responses. Kumar et al. (2017) performed the mixed-mode fracture analysis of multiple cracks in flat and curved stiffened panels based on stress intensity factor, which measures the stress density around the crack tip, by using numerical and experimental methods. Zhang et al. (2018) investigated the harmonic response of coupled plate structures based on the dynamic stiffness method, which makes possible to model a structure having an inifinite number of natural modes via mathematical expressions with the finite number of degrees of freedom. Ozdemir et al. (2018) performed a buckling analysis of stiffened plates. The dynamic behavior of the stiffened plates is based on the effective mesh-free model. Babazadeh and Khedmati (2018) investigated the ultimate strength behavior of cracked ship structural elements. Minh et al. (2018) examined the stability of cracked plates. They considered a rectangular cracked plate with variable thickness and analyzed based on the FSDT and the phase-field method. Zeng et al. (2019) searched the breathing-crack, which opens when it is deformed and closes when the effect that causes the deformation removes, for beam-like structures. They analyzed the vibration responses under different conditions. Phase-field buckling analysis of a stiffened functionally graded plate with cracks has been examined by Hoai et al. (2019). The plate bending element has been integrated into the numerical manifold method to perform vibration analysis by Hongwei et al. (2019). Isanaka et al. (2020) presented free vibration analysis of simply supported plates with arbitrary shapes. The plates have been modelled in a curvilinear shape with a stiffener. The harmonic response of a Minden Deutz type bogie of a passenger coach wheelset based on the finite element method has been determined by Cruceanu and Sorohan (2020). The nonlinear vibration of cracked Mindlin plate with in-plane preload has been investigated by Xue et al. (2020). The energies of the plate have been constructed based on von Kármán's nonlinear plate theory. Abed and Majeed (2020) presented a modified Fourier-Ritz approach to study the dynamic transverse response of laminated plates with different boundary conditions. The effect of crack depth and location on the beam deflection response has been examined has been investigated by Al-Zubaidi et al. (2020). The effect of crack location on buckling and dynamic stability in plate frame structures has been investigated by Gonenli and Das (2021). Singh and Pal (2021) examined the impact of the surrounding 
fluid on the stiffened lock gate structure subjected to an external sinusoidal acceleration. Gonenli et al. (2021) investigated the free vibration behavior of a pre-stressed curved plate with crack. Alavi and Eipakchi (2021) presented the dynamic response of the annular sector plates under asymmetric impulsive and harmonic transverse loads based on Hamilton's principle.

Crack occurrence can be observed in any kind of engineering structure due to several reasons such as fatigue, deterioration of the internal structure of the material, excessive loading conditions that compel strength of the structure. The common consequence of a crack occurrence is that it reduces the integrity of the structure. Therefore, it becomes essential to measure the impact of a crack on the mechanical properties of a structure. As it is summarized above, various studies are comprising the dynamic behavior of healthy or damaged engineering structures. On the other hand, to the best of the Authors' knowledge, the effects of the crack and its location on the harmonic response of stiffened plates have not been measured yet. This study aims to create insight for engineers and researchers in that topic by presenting the effects of the crack location on the first three natural frequencies, and displacement response of the stiffened plates under fixed from stiffened edges and fixed from non-stiffened edges boundary conditions. For this purpose, the free vibration and harmonic response analyses have been performed using the Finite Element Method via ANSYS Workbench 18.2. Horizontal and vertical cracks have been modelled considering to be located throughout the entire structure and along the stiffener. To perform the harmonic response analysis, the Mode Superposition Method has been employed. The contributions of the study can be summarized as follows.

1. (i) Measuring the impact of the crack location on the harmonic response of stiffened plates.

2. (ii) Investigating the effects of the stiffener cracks on the harmonic response of the stiffened plate structures.

3. (iii) Examining the relation among the crack length, direction, boundary conditions, and the dynamic behavior of the stiffened structures.

\section{ANALYSIS AND VERIFICATION}

The effect of the crack location on the stiffened plates has been measured considering the square stiffened structure shown in Figure 1. The dimension of the plate is $203.2 \times 203.2 \times 1.376 \mathrm{~mm}(\mathrm{a} \times \mathrm{a} \times \mathrm{h})$. The plate structure is stiffened with a rectangular beam whose height and width are $12.7 \mathrm{~mm}$ and $6.35 \mathrm{~mm}$ ( $a_{\text {stiff }} \times h_{\text {stiff), }}$, respectively (Hamedani et al., 2012). The cracks have been modelled as parallel to the stiffened edges (horizontal cracks) and as parallel to the non-stiffened edges (vertical cracks). In addition to the two different crack directions, two crack length values have been considered for the entire structure and stiffener, individually. The cracks modelled for the entire structure have $20.32 \mathrm{~mm}$ crack length for both vertical and horizontal cracks. This type of crack has been denoted as "plate crack". For each crack direction (horizontal or vertical) 35 locations ( 15 for left and right side of the stiffener and 7 for the stiffener-plate intersections) in the entire structure have been considered to investigate the location-based effects of the crack. The length of the crack considered to exist only on the stiffener is chosen as $5.08 \mathrm{~mm}$. This kind of crack has been represented as "stiffener crack". The width of those cracks is selected as $1 \mathrm{~mm}$. The crack depth is equal to the thickness of the structure. Their directions are considered the same as those of plate cracks.

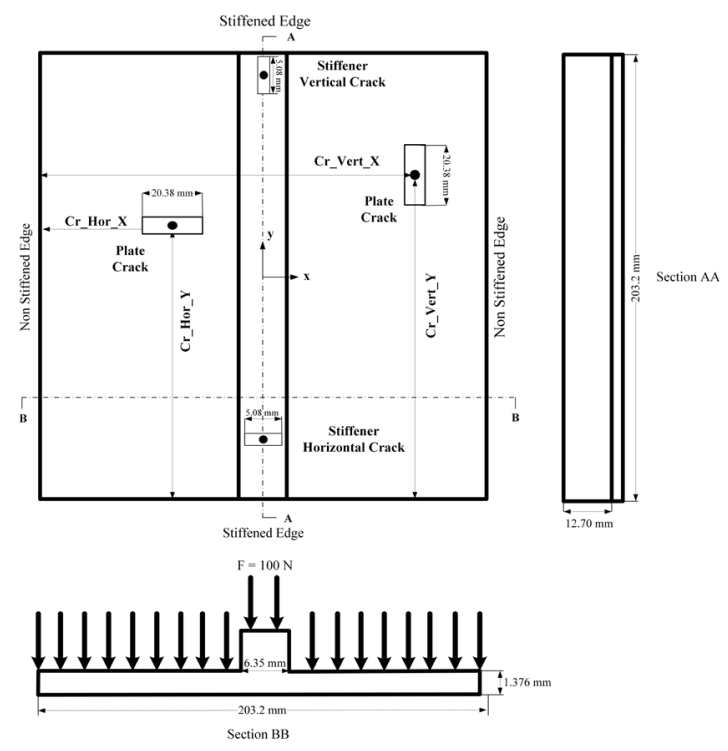

Figure 1 Stiffened cracked plate under distributed harmonic loading 
As seen from Figure 1, the abbreviations "Hor" for horizontal cracks and "Vert" for vertical cracks have been considered. The position of the crack has been denoted as " $\mathrm{Cr} r_{-} \mathrm{Hor}_{-} X^{\prime \prime}$, " $\mathrm{Cr} r_{-} \mathrm{Hor}_{-} \mathrm{Y}^{\prime}$ " and "Cr_Vert_X", "Cr_Vert_Y". All analyses have been performed considering two boundary conditions shown in Figure 2 . The first boundary condition is fixed from stiffened edges and the second one is fixed from non-stiffened edges. The free vibration and harmonic response analyses have been performed for each crack size, location, and direction. The procedure that is conducted via ANSYS for this study is presented in Figure 3. The mathematical expressions related to modal and harmonic analyses are presented in Appendix 1.

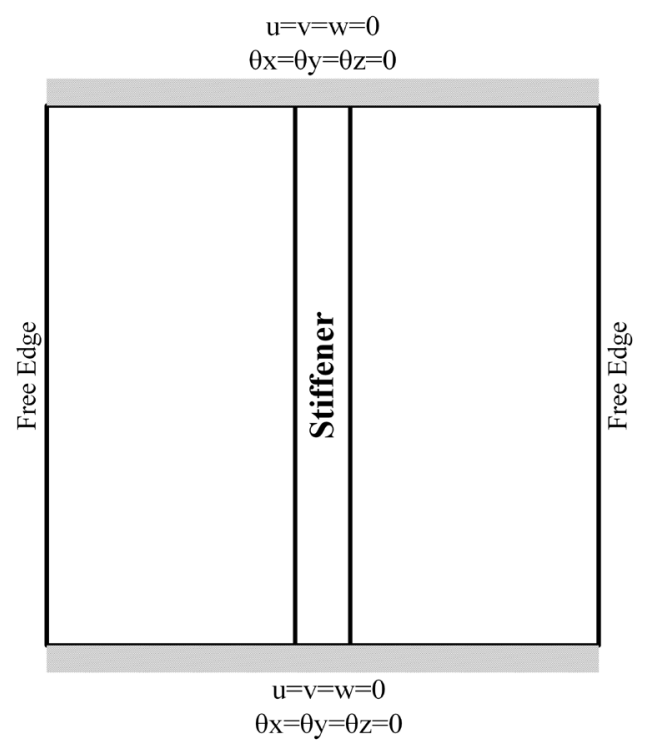

(a)

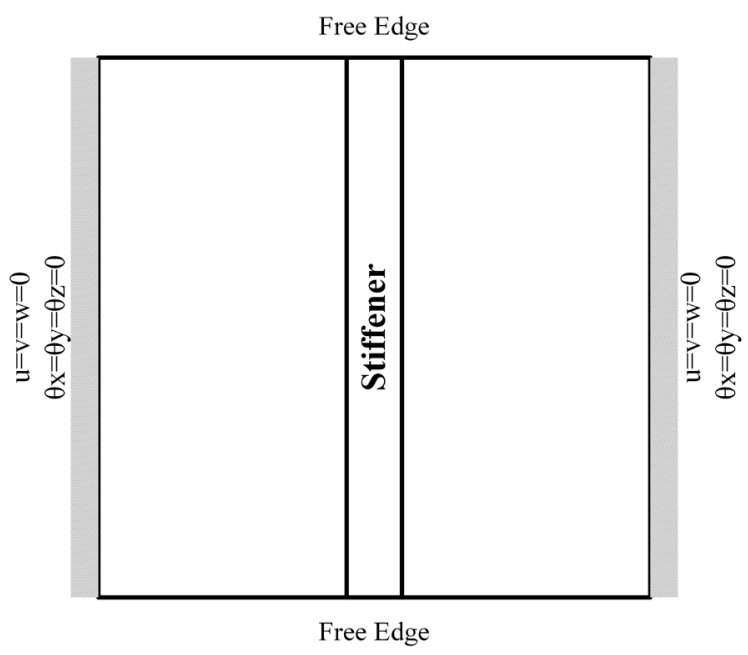

(b)

Figure 2 (a) Fixed from stiffened edges and (b) fixed from non-stiffened edges boundary conditions

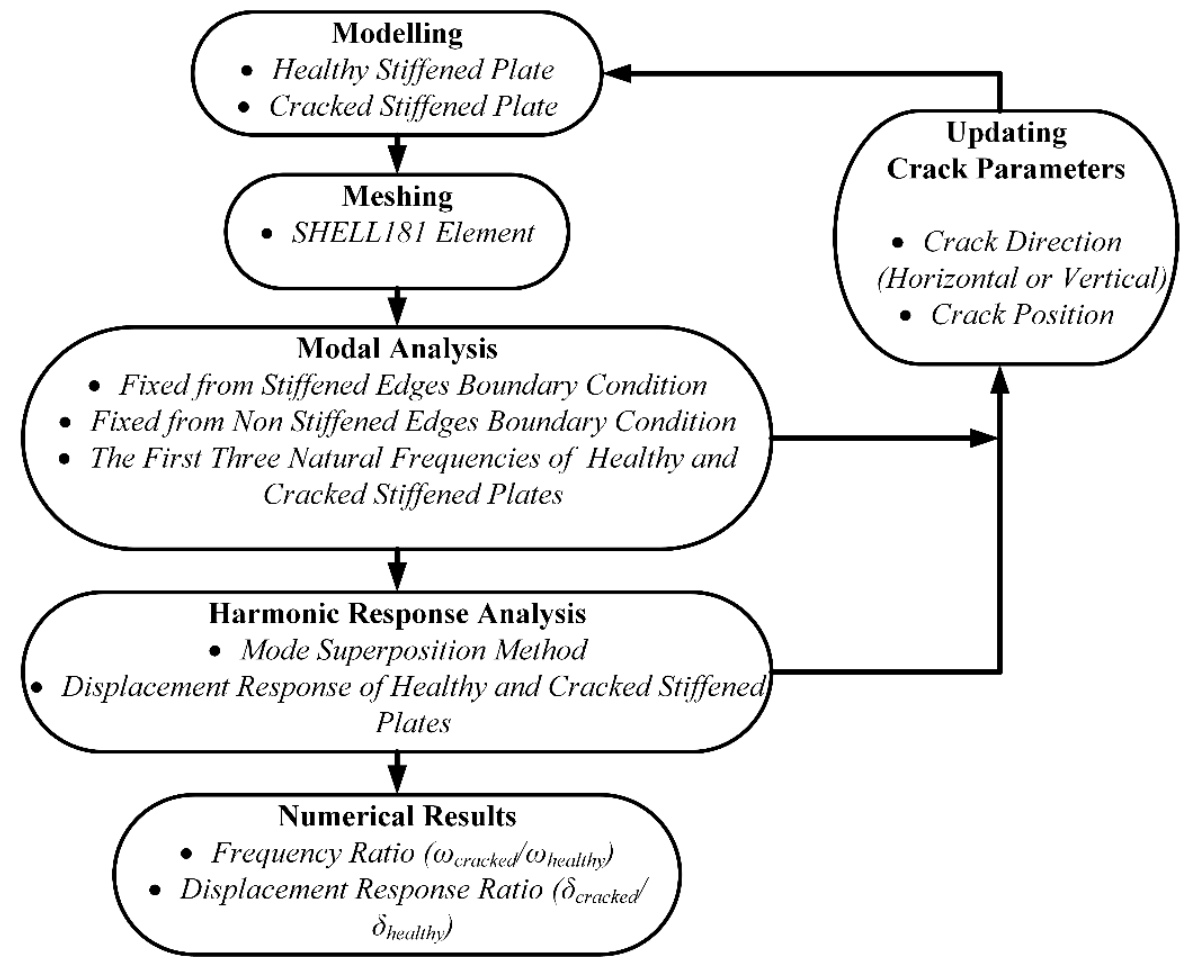

Figure 3 The flowchart of the free vibration and harmonic response analyses

As seen from Figure 3, the healthy and cracked stiffened plates have been modelled in ANSYS Workbench using Design Modeller module. Structural steel, whose properties are given in Table 1, has been selected as the material of 
stiffened structures. The free vibration analyses for both healthy and cracked stiffened plate structures have been conducted to evaluate the first three natural frequencies of those structures considered two boundary conditions as shown in Figure 2. For this purpose, both healthy and cracked structures have been meshed using the SHELL 181 element, which satisfies the required degree of freedom to model the thin stiffened structure. Figure 4(a) shows the considered four-node tetrahedral element with six degrees of freedom at each node comprising the translations in the $x, y$, and $z$ directions, and rotations around the $x, y$, and z-axes. To improve the accuracy of the results, the adaptive mesh refinement technique (Berger, $M$. and Oliger, J. 1983) has been chosen considering the $4 \mathrm{~mm}$ mesh size. Figure 4(b) shows the meshed structure by considering the parameters mentioned above. Afterward, the harmonic response analysis has been performed to obtain the displacement response of healthy and cracked stiffened plate structures under fixed from stiffened edges and fixed from non-stiffened edges boundary conditions. To conduct the harmonic response analysis a uniformly distributed force with $100 \mathrm{~N}$ magnitude has been applied to the upper surface of the structure as shown in Figure 1. As the solution method, the Mode Superposition Method has been employed. Instead of calculating the displacement of each node during the analysis, the Mode Superposition Method uses the mode shapes, which are evaluated from the Free Vibration Analysis. Thanks to this technique, it solves the problem faster than the Full Method without reducing the accuracy (Ramesha et al. 2015). The frequency range has been selected in such a way that it comprises the fundamental and the third natural frequencies of the structures. By doing so, the displacement responses that may take place at those or around these frequencies have not been missed. The damping characteristic of the structure has been defined as a constant damping ratio, which is chosen as $\xi=0.02$ (Kiral, 2014). The procedure mentioned above has been performed for each crack size and location.

Table 1 The material model of structural steel

\begin{tabular}{ccc}
\hline Property & Symbol & Value \\
\hline Modulus of Elasticity & $\mathrm{E}$ & $200 \mathrm{GPa}$ \\
Shear Modulus & $\mathrm{G}$ & $76.92 \mathrm{GPa}$ \\
Density & $\rho$ & $7850 \mathrm{~kg} / \mathrm{m}^{3}$ \\
Poisson's Ratio & $\mathrm{U}$ & 0.3 \\
\hline
\end{tabular}

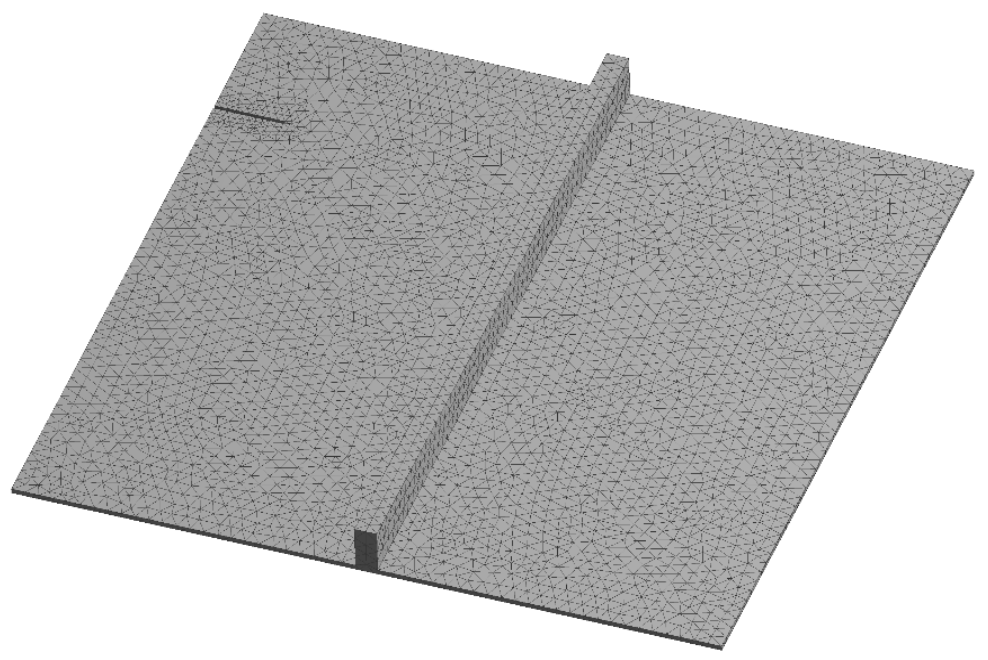

(a)

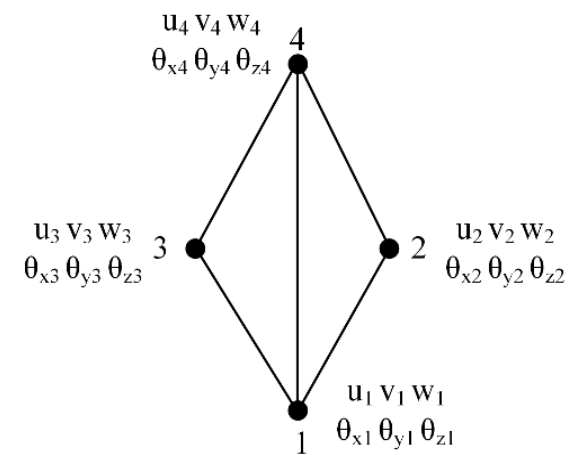

(b)

Figure 4 (a) The Finite Element Model of the structure and (b) employed tetrahedral element

To validate the considered modeling technique, a validation analysis has been performed. Therefore, the employed model has been validated by experimental results reported by Olson and Hazell (1977) and theoretical studies presented by Koko and Olson (1992) and Hamedani et al. (2012).

Table 2 presents the non-dimensional natural frequencies, which can be calculated by equation (1). According to the results given in Table 2, the considered model is in good agreement with other studies that existed in the literature. 


$$
\left(\omega_{d}=\omega a^{2} \sqrt{\frac{\rho(1-v)^{2}}{12 E h^{2}}}\right)
$$

Table 2 Validation analysis results of the present study considering four sides fixed boundary condition and non-dimensional natural frequencies

\begin{tabular}{ccccc}
\hline Mode & $\begin{array}{c}\text { Olson and Hazell } \\
(\mathbf{1 9 7 7 )}\end{array}$ & $\begin{array}{c}\text { Hamedani et al. } \\
\mathbf{( 2 0 1 2 )}\end{array}$ & $\begin{array}{c}\text { Koko and Olson } \\
(\mathbf{1 9 9 2 )}\end{array}$ & Present Study \\
\hline 1 & 63.855 & 64.026 & 68.285 & 68.821 \\
2 & 67.191 & 67.444 & 71.306 & 72.790 \\
3 & 89.063 & 87.100 & 94.531 & 94.595 \\
4 & 91.380 & 88.026 & 95.643 & 95.976 \\
5 & 127.524 & 123.200 & 137.533 & 133.345 \\
\hline
\end{tabular}

\section{NUMERICAL RESULTS}

Free vibration and harmonic response analysis results have been obtained by positioning the horizontal and vertical cracks. Figures 5 and 6 show the first three modes of the healthy stiffened plates fixed from stiffened edges and non-stiffened edges, respectively.
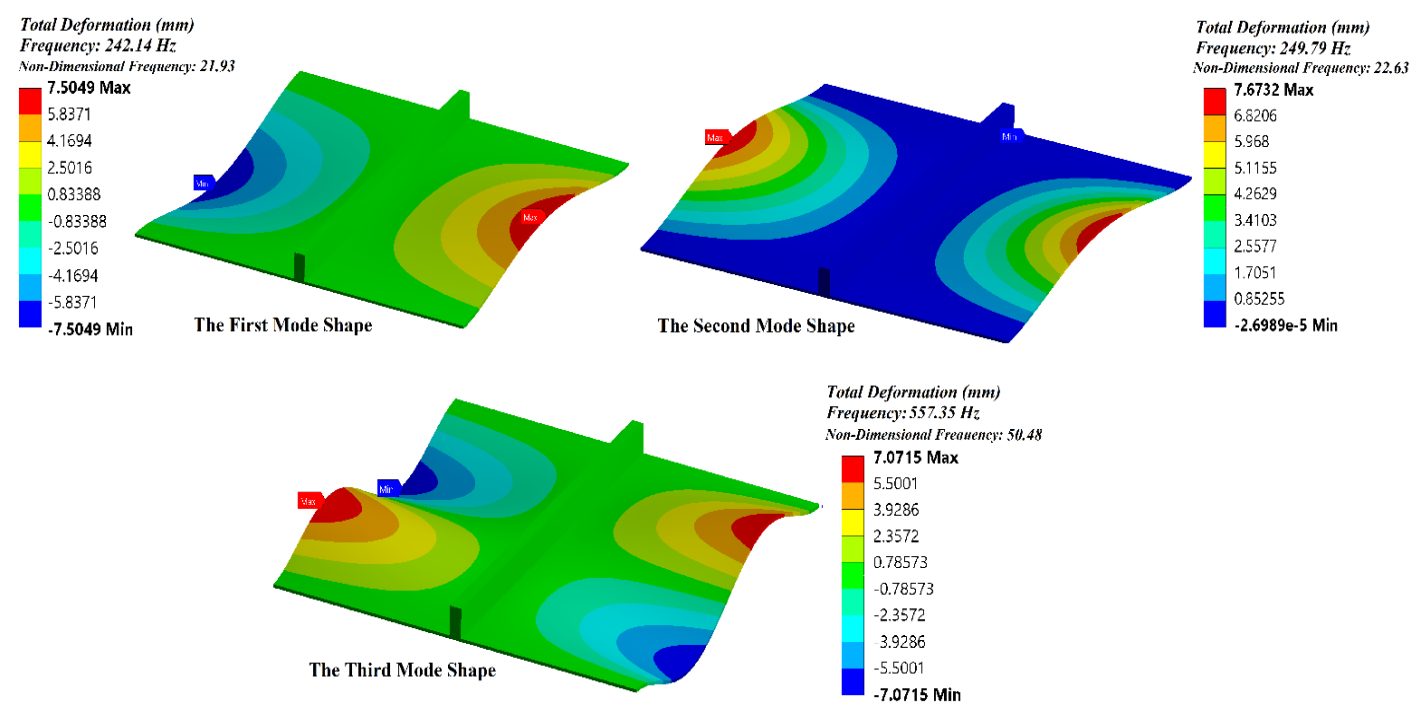

Figure 5 The first three mode shapes of the healthy stiffened plates fixed from stiffened edges

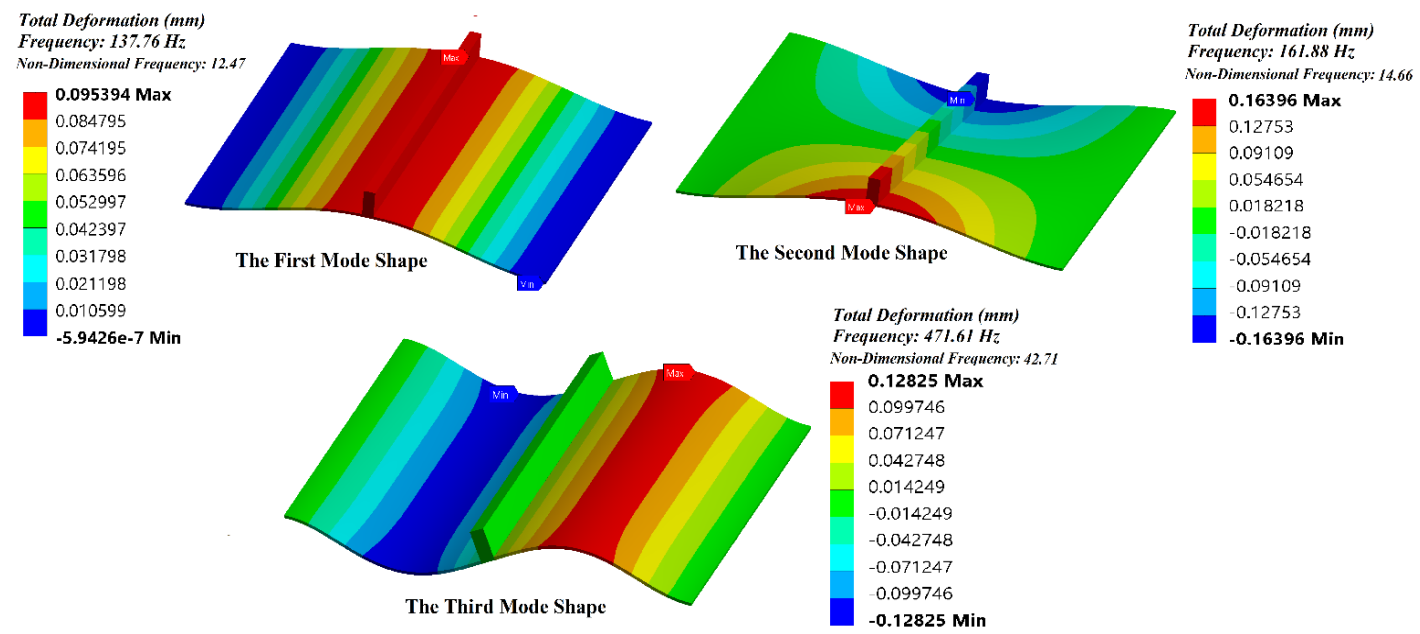

Figure 6 The first three mode shapes of the healthy stiffened plates fixed from non-stiffened edges 
It is seen from Figures 5 and 6 that the mode shapes vary with respect to the fixed (clamped) edge. The structure behaves in bending modes at the first three natural frequencies no matter which edges are fixed. No torsional or torsional-bending coupled modes have been observed for these frequencies. Such modes may occur as the structure vibrates at further frequencies. It is seen from Figure 5 that the bending displacement of the structure reaches its absolute maximum value at the midpoint of the free edges (non-stiffened edges). The bending behavior has not been observed in the entire structure as it is fixed from its stiffened edges. The displacement becomes negligible along the fixed edges (stiffened edges), stiffener, and close-to-center regions of the structure. This may take place due to restricting the degrees of freedom of the stiffened edges, which provided additional stiffness to the structure. The reciprocal bending regions of the first and third mode shapes of the structure fixed from its stiffened edges are symmetrical to each other. The number of bending regions of the first mode shape is increased from two to four (two in each free edge) for the third mode shape. Such an increment has formed the bending regions at each free edge sinusoidally. Although the first two mode shapes of the structure fixed from stiffened edges look similar to each other, they differ by bending directions of the free edges as seen in Figure 5. The free edges bend in opposite direction at the fundamental and third natural frequency, while those edges bend in the same direction at the second natural frequency. It is seen from Figure 6 that the bending behavior of the structure differs as it is fixed from its non-stiffened edges. Therefore, the first mode shape of the structure fixed from non-stiffened edges corresponds to pure bending. On the other hand, the second mode shape is similar to the first mode shape of the structure fixed from stiffened edges. Hereunder, the maximum bending displacement has been observed at the midpoint of the free edges (in this case, it is stiffened edges). Just as the first mode shape, shown in Figure 6, the bending displacement becomes negligible (zero-displacement) around the central region of the structure and along the fixed edges (non-stiffened edges). Comparing the second mode of the structure fixed from its non-stiffened edges with the first mode shape of the structure fixed from stiffened edges, it is seen that the zerodisplacement region of the second mode shape of the structure, fixed from its non-stiffened edges is narrower. The third mode is the second harmonic sinusoidal form of the pure bending mode shape as shown in Figure 6.

Comparing the mode shapes shown in Figure 4 and Figure 5, the structure fixed from stiffened edges bend from its free ends in all three modes, while the bending behavior takes place throughout the plate for the structure fixed from the non-stiffened edges. Besides, as seen in Table 3, the first three natural frequencies of the structure fixed from stiffened ends are higher than those fixed from the non-stiffened edges. The difference comes from the reduced stiffness matrix due to the applied boundary condition. Constraining the structure from the stiffened ends resulted in higher force or moment reactions when compared to the structure fixed from non-stiffened edges. The stiffener plays an important role since it stiffens the structure, reducing its bending movement. Therefore, additional constraint, which is applied to the stiffener increases the natural frequency of a structure. The displacement values obtained from the modal analysis are representative but do not reflect the actual value since the displacements correspond to eigenvectors that are obtained from the eigenvalue problem, which is derived from the equation of motion (Petyt, 2010) (See Appendix). Therefore, the displacement values are scaled values, but yet contain significant information, especially for the comparison of the multiple structures' displacement behavior. Hence, the displacement behavior of the structures under two different boundary conditions, it is seen that constraining the structure from its non-stiffened edges resulted in lower displacement values in all three vibrational modes when compared with those of the structure fixed from its stiffened edges. Fixing the non-stiffened edges prevent the structure from larger displacements since the stiffness of the stiffened structure is lower at the non-stiffened regions when compared with the stiffener and regions close to the stiffener.

Figure 7 shows the variations of the first three natural frequencies of stiffened plates fixed from the stiffened edges and having horizontal plate cracks considering the ratios of the frequency values of cracked structure to those of healthy ones ( $\left.\omega_{\text {cracked }} / \omega_{\text {healthy }}\right)$.
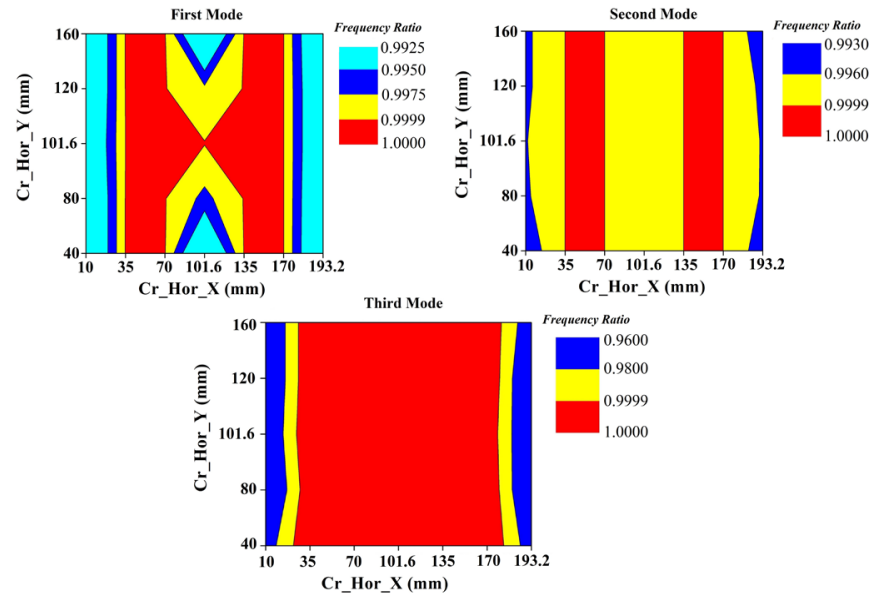

Figure 7 The first three frequency ratios $\left(\omega_{\text {cracked }} / \omega_{\text {healthy }}\right)$ of the stiffened plates fixed from stiffened edges having a horizontal crack at different locations 
Table 3 First three non-dimensional natural frequencies of stiffened plates under two boundary conditions

Non-Dimensional Natural Frequencies

\begin{tabular}{ccc}
\hline Mode & Fixed from Stiffened Edges & Fixed from Non Stiffened Edges \\
1 & 23.008 & 13.110 \\
2 & 23.745 & 15.394 \\
3 & 52.948 & 44.784 \\
\hline
\end{tabular}

It is seen from Figure 7 that the first three natural frequencies change for the structure fixed from stiffened edges in the presence of horizontal plate crack. On the other hand, the most considerable frequency decrement has been obtained by about $4 \%$ for the third mode when the crack occurs at the free edges. This situation also caused a change in the third mode shape as seen in Figure 8. Two of the bending zones located at the opposite side of the crack are diminished due to the stiffness reduction effect of the crack. Such an outcome has been observed in all structures under fixed from stiffened edges boundary condition and have a crack located along the free edges (non-stiffened edges for fixed from stiffened edge boundary condition). As the crack moves toward stiffener from the free edges of the structure, decrement of the third natural frequency of the structure diminishes by $2 \%$. This situation creates another region indicated by yellow in Figure 7 (see the Third Mode). The difference in the third natural frequency of the structure becomes negligible for the remained parts of the structure. The first two natural frequencies have also been affected by the crack. However, this effect can be considered negligible since the crack decreases the first two natural frequencies up to $0.75 \%$. The first two mode shapes remain the same as shown in Figure 5 since the crack has only affected the stiffness of the structure in such a way that it only changes the third mode shape when it occurs along the non-stiffened edges. This can be related to the slope and number of the bending zones. As seen in Figures 5 and 8 , there are two bending zones per free edge in the third mode. On the other hand, there is a single bending zone for the first two mode shapes of the structure fixed from stiffened edges. Besides, the slope bending zones of the third mode is higher than that of the first two mode shapes. The first three natural frequencies differ symmetrically as the crack location changes from one non-stiffened edge to the other. This is because the bending zones in the mode shapes shown in Figure 5 occur at the non-stiffened edges of the structure. Therefore, as seen from Figure 7, the cracks located along the free edges of the structure have more impact on the natural frequencies of the stiffened structures. On the other hand, it is observed that the crack occurrence on the stiffener (near the fixed stiffened edge) also affects the fundamental frequency just like those of occurred along the free non-stiffened edges. The effect of the crack becomes negligible as it occurs around the middle region of the structure. This is because no bending has been observed in the middle region of the structure when vibrating at corresponding (first three) mode shapes.
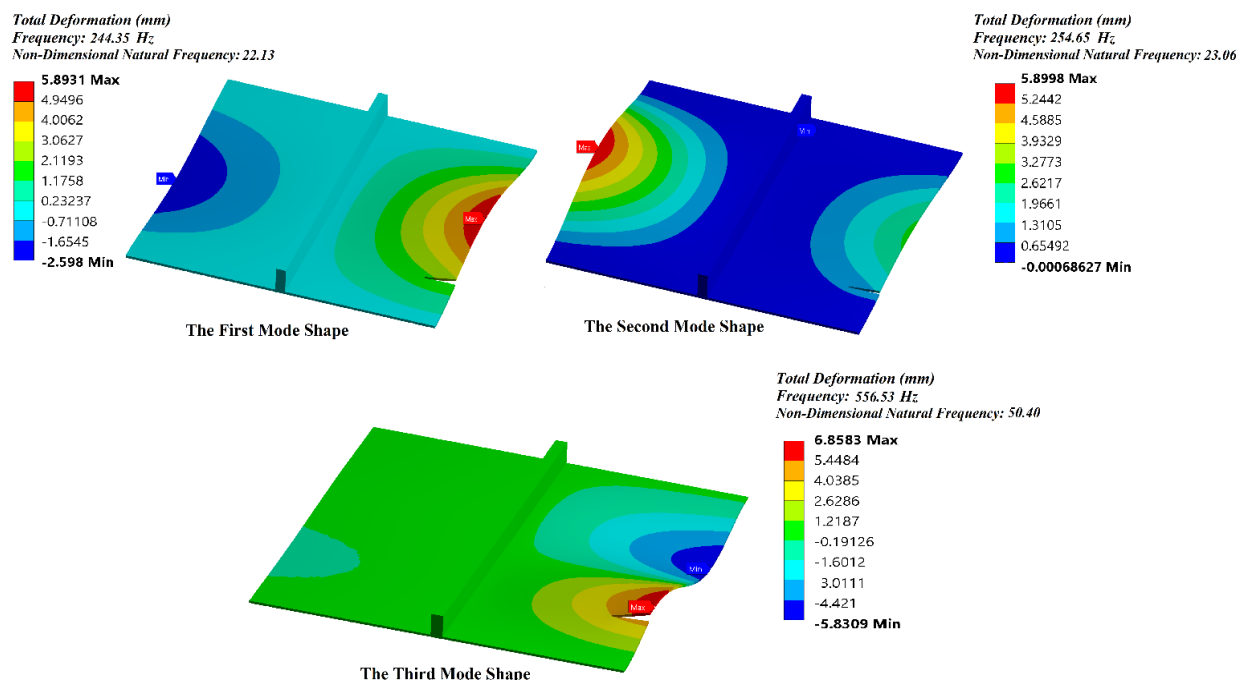

Figure 8 The third mode shape of the stiffened plates fixed from stiffened edges and having a horizontal crack around the free edges

Figure 9 shows the changes in the first three natural frequencies of stiffened plates fixed from the non-stiffened

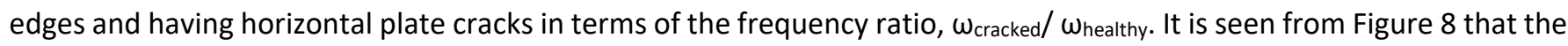


first two natural frequencies are not affected by the crack no matter where it is located since the first two natural frequency values remain almost the same as that of healthy ones. The difference between the first two cracked and healthy frequencies is smaller than $0.001 \%$. This is because the horizontal crack has not considerably affected the stiffness components of the structure, which are related to the first two natural frequencies. Besides, the thickness of the structures may also play a role in such a difference. On the other hand, the crack occurrence in the middle of the stiffener caused a significant drop in the third natural frequency. The third natural frequency is decreased by about $60 \%$ as the crack occurs in the middle of the stiffener. Such a considerable change also caused a difference in the third mode when compared with that of the healthy structure, as seen in Figure 10. This is because the stiffness components for the third natural frequency of the structure have been considerably reduced as a horizontal crack with $20.38 \mathrm{~mm}$ length occurs in the middle of the structure. This effect decreased as the crack moves away from the stiffener.
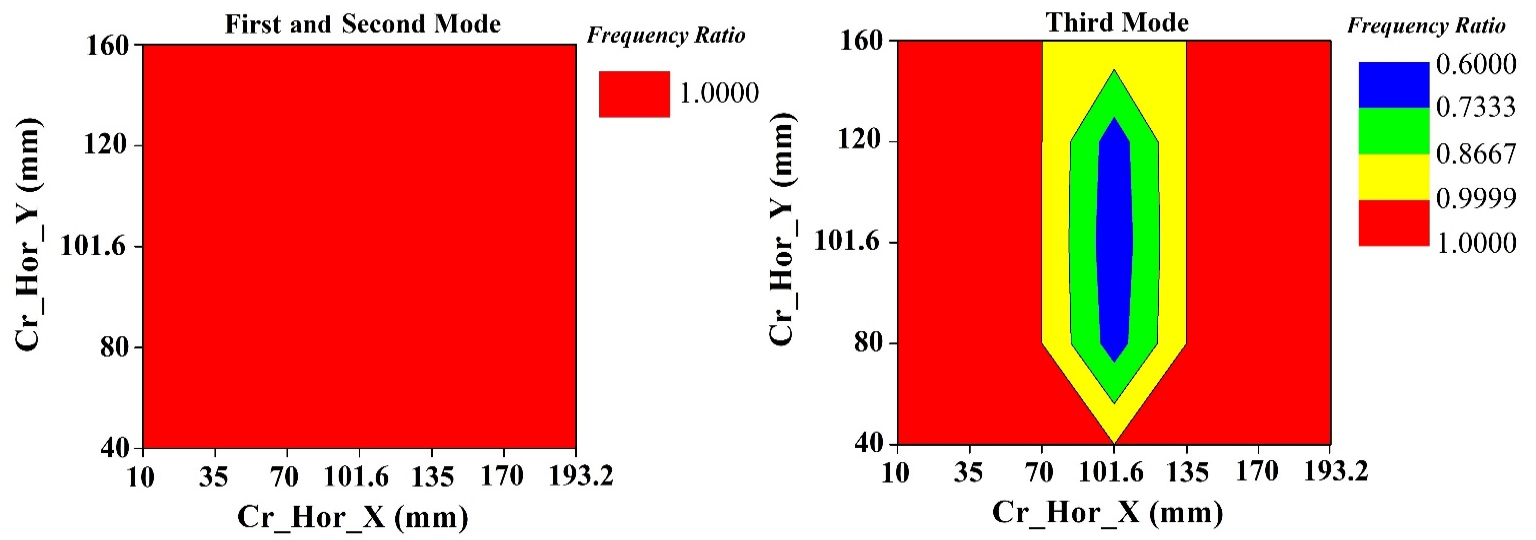

Figure 9 The first three frequency ratios $\left(\omega_{\text {cracked }} / \omega_{\text {healthy }}\right)$ of the stiffened plates fixed from non-stiffened edges having a horizontal crack at different locations

Figure 10 shows the third mode shape of the stiffener plate having a central crack whose length encompasses both the stiffener and plate.
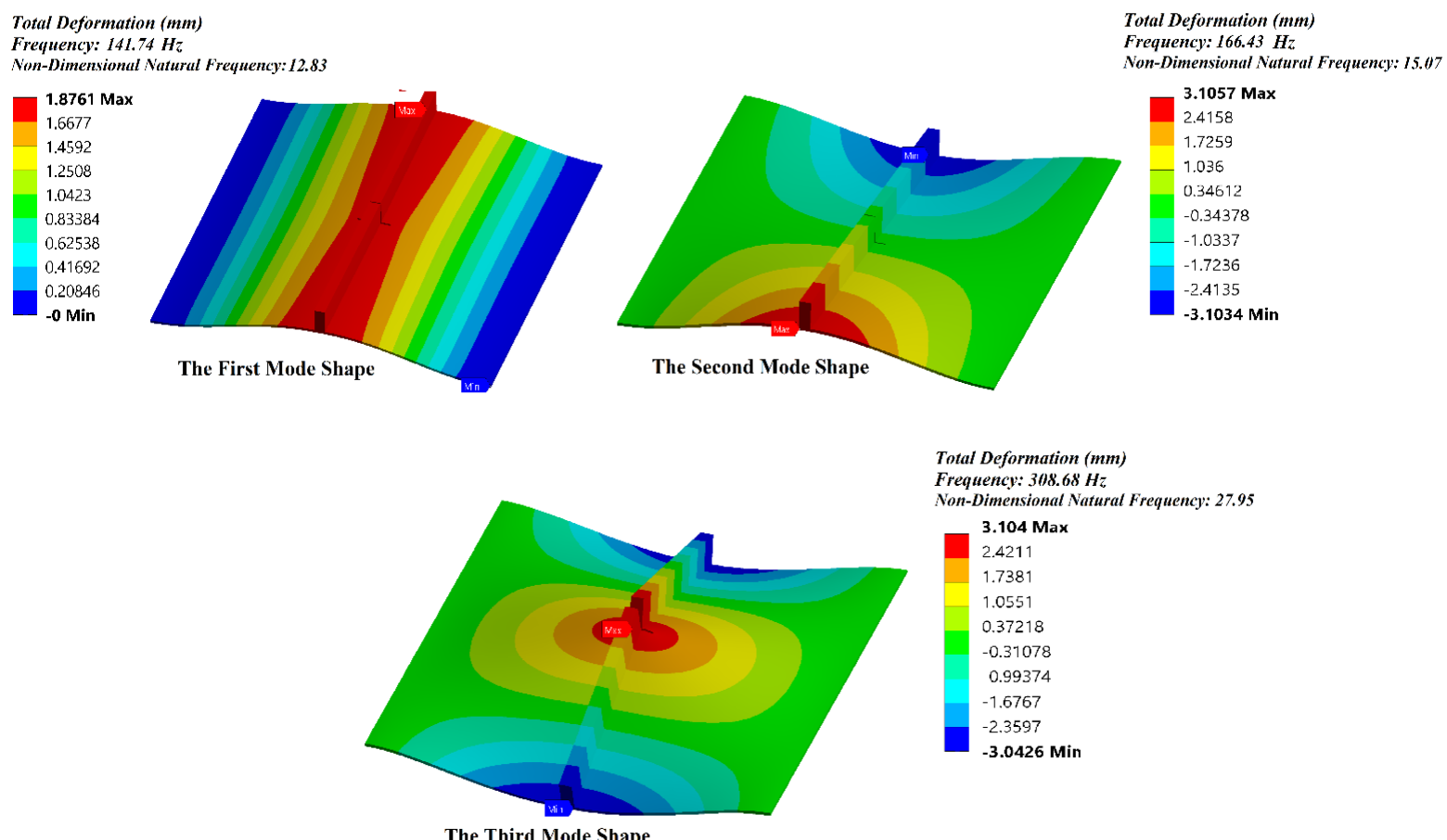

Figure 10 The third mode shape of the stiffened plates fixed from non-stiffened edges and having a central horizontal crack 
It is seen from Figure 10 that a central horizontal crack occurrence has changed the third mode and affected the size of the first mode shape's bending zone sizes of the structure. Besides, it increases the maximum total deformation of all mode shapes when compared with that of the healthy one. The horizontal plate crack narrows the size of the maximum bending zone of the first mode shape. The second mode shape has not changed or been impacted by the horizontal plate crack since it has taken place on the bending regions of the corresponding mode shape of the structure. The same crack, on the other hand, has changed the third mode shape completely. As seen from Figure 5, the bending slope of the structure becomes maximum along the stiffener where the horizontal plate crack has occurred. Therefore, it can be concluded that the crack affects the mode shape if it exists in the bending zones of the corresponding mode shape, but it completely changes the mode shape if it occurs in the region where the maximum bending slope is observed.

Since the vibrational behavior of a structure depends on the parameters (i.e., the geometry of the structure, material, constraints, and damage) that affected the stiffness and mass matrices of the structure, the cause of such changes can be related to the crack length and position. Hence, it can be concluded that a horizontal plate crack located on the stiffener and the center of the stiffened plate structure has affected the stiffness of the structure in such a way that it changed or affected the mode shapes of the structure. The impact of the horizontal plate crack located on the stiffener is much considerable than other cracks since it penetrates both the width and thickness of the stiffener. Therefore, the integrity of the structure has been affected by those cracks more than the other cracks, which are located elsewhere. The frequencies and the corresponding maximum displacement responses, which occur at those frequencies have been presented in Table 4. It is seen from Table 4 that the maximum response of the structure fixed from stiffened edges occurs around the second natural frequency, whereas it takes place around the fundamental frequency for the structure fixed from non-stiffened edges. The displacement response of the structure fixed from non-stiffened edges is higher than those of fixed from the stiffened edges. The results of the cracked structures have been evaluated considering the ratio of the response values of the healthy structure over those of the cracked structure. Figure 11 shows the response ratio $\left(\delta_{\text {cracked }} / \delta_{\text {healthy }}\right)$ and the highest response distribution map evaluated for stiffened plate structures under fixed from stiffened edges and fixed from non-stiffened edges boundary conditions and having a horizontal crack.

Table 4 Maximum displacement response of healthy stiffened plates

\begin{tabular}{ccc} 
Boundary Condition & $\begin{array}{c}\text { Maximum Displacement Response } \\
\text { (mm) }\end{array}$ & $\begin{array}{c}\text { Non-Dimensional Maximum Displacement Response } \\
\text { Frequency }\end{array}$ \\
\hline Fixed from Stiffened Edges & 0.455 & 23.008 \\
Fixed from Non-Stiffened Edges & 0.553 & (at the Second Natural Frequency-254 Hz) \\
& & (at the First Natural Frequency-143 Hz) \\
\hline
\end{tabular}
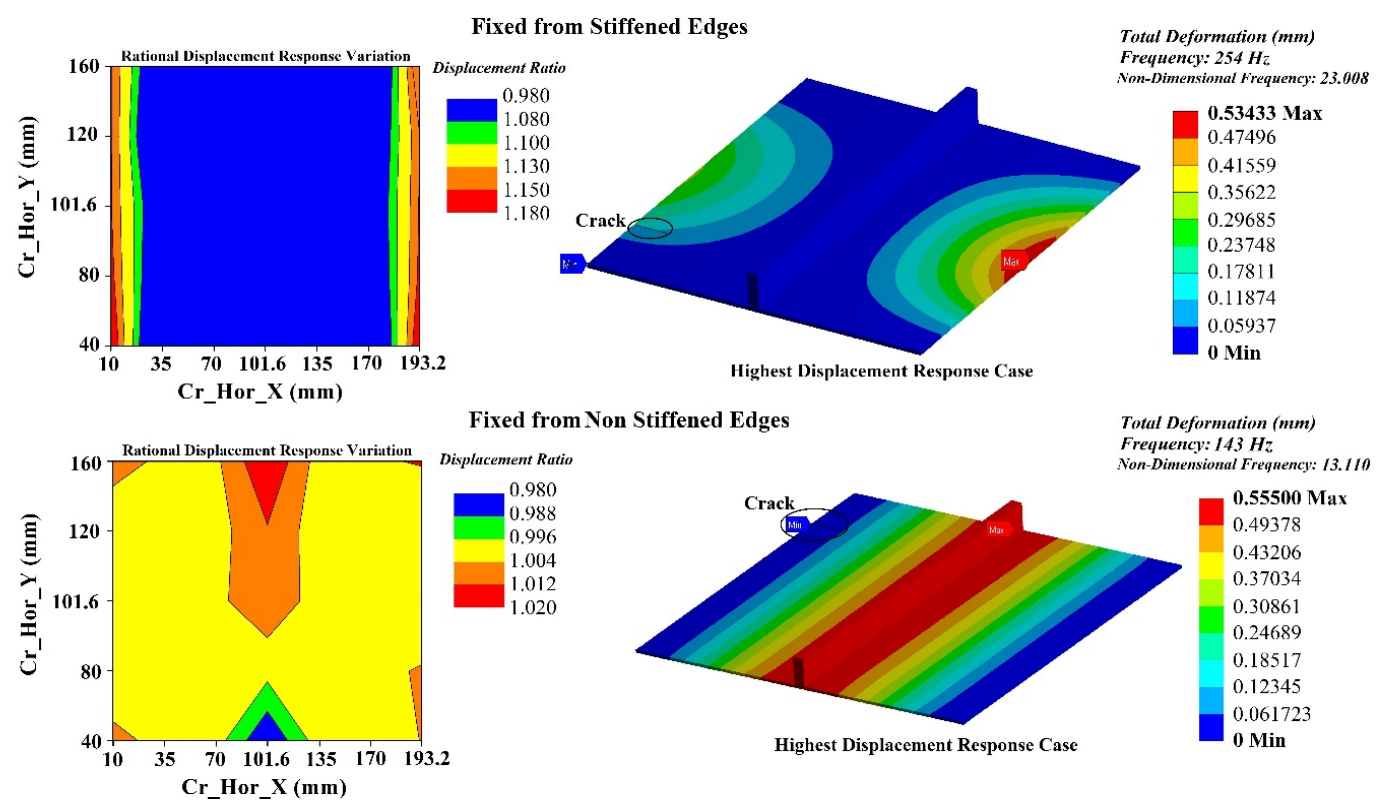

Fixed from Non Stiffened Edges
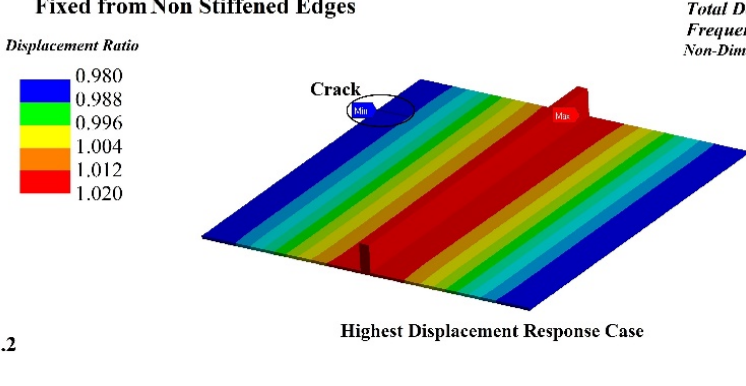

Total Deformation (mm) Frequency: $143 \mathrm{~Hz}$ $0.55500 \mathrm{Max}$ 0.49378 0.43206 0.43206
0.37034 0.30861 0.30861
0.24689 0.18517 0.12345 0.12345 0.06172 Highest Displacement Response Case 0 Min

Figure 11 The displacement response ratios $\left(\delta_{\text {cracked }} / \delta_{\text {healthy }}\right)$ and highest displacement responses of the horizontally cracked stiffened plates under two different boundary conditions 
It is seen from Figure 11 that the horizontal crack affects the harmonic response of the structure in different ways in accordance with the applied boundary condition. The crack increases the displacement response when it occurs along the free sides for the structure fixed from stiffened edges. On the other hand, this increment is limited for the corners and the half of the stiffener for the structure fixed from non-stiffened edges. Comparing the crack effect levels, it is seen that the horizontal crack that occurred along the side of the structure fixed from stiffened edges affects more than that of located at the critical regions in the structure fixed from non-stiffened edges. The highest displacement response case maps illustrate the highest displacement response occurs for the most critical crack location. The maps indicate that the displacement distribution is almost the same as the corresponding mode shape of the structure, as shown in Figures 5 and 6. On the other hand, the horizontal plate crack that located at the free edge of the structure fixed from stiffened ends suppresses the maximum bending region that occurs at the free edge where the crack takes place. The crack occurrence does not change the mode shape and the maximum displacement region since it slightly decreases the stiffness of the structure. However, the maximum deformation values of the highest displacement response cases, shown in Figure 11 indicate that such a reduction in the stiffness of the structure resulted in an increment in the maximum deformation value of stiffened plate for all boundary conditions. As seen from Table 4 and Figure 11, the maximum displacement response of the cracked structure is increased by approximately $18 \%$ when compared with that of the healthy structure considering fixed from stiffened edges boundary conditions. On the other hand, the maximum displacement response of the cracked structure under fixed from non-stiffened edges boundary condition is increased or decreased by about $2 \%$ when compared with that of healthy. Such a small difference indicates that the horizontal crack does not have a considerable impact on the stiffness of the structure to change its maximum displacement response under a harmonic load.

Figure 12 shows the highest displacement response cases of the stiffened structures under fixed from stiffened edges and fixed from non-stiffened edges boundary conditions.
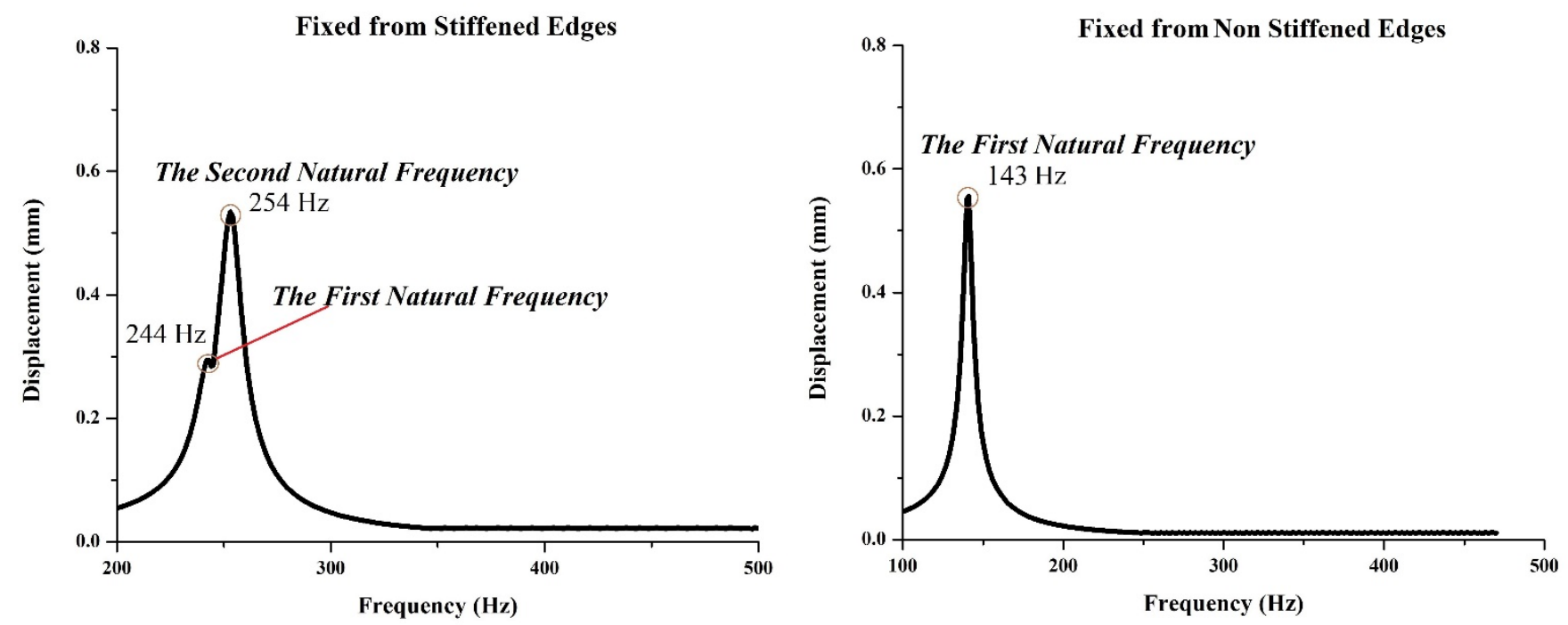

Figure 12 The critical frequency-displacement response diagram of stiffened plates under two different boundary conditions and having a horizontal crack

It is seen from Figure 12 that the maximum response takes place at the second natural frequency and first natural frequency for the structure under fixed from stiffened edges and fixed from the non-stiffened edges, respectively. For the structure fixed from stiffened edges, another peak is observed at the fundamental frequency. However, this peak is considerably smaller than that occurred at the second natural frequency. Such an additional peak is not seen for the structure fixed from the non-stiffened edges. Therefore, it can be concluded that the boundary condition and crack location do not only change the frequency region where maximum response occurs, but also may generate noteworthy peaks.

Figure 13 shows the changes of the first three natural frequencies of stiffened plates fixed from the non-stiffened edges and having vertical plate cracks considering the ratios of the frequency values of cracked structure to those of healthy ones ( $\left.\omega_{\text {cracked }} / \omega_{\text {healthy }}\right)$. 

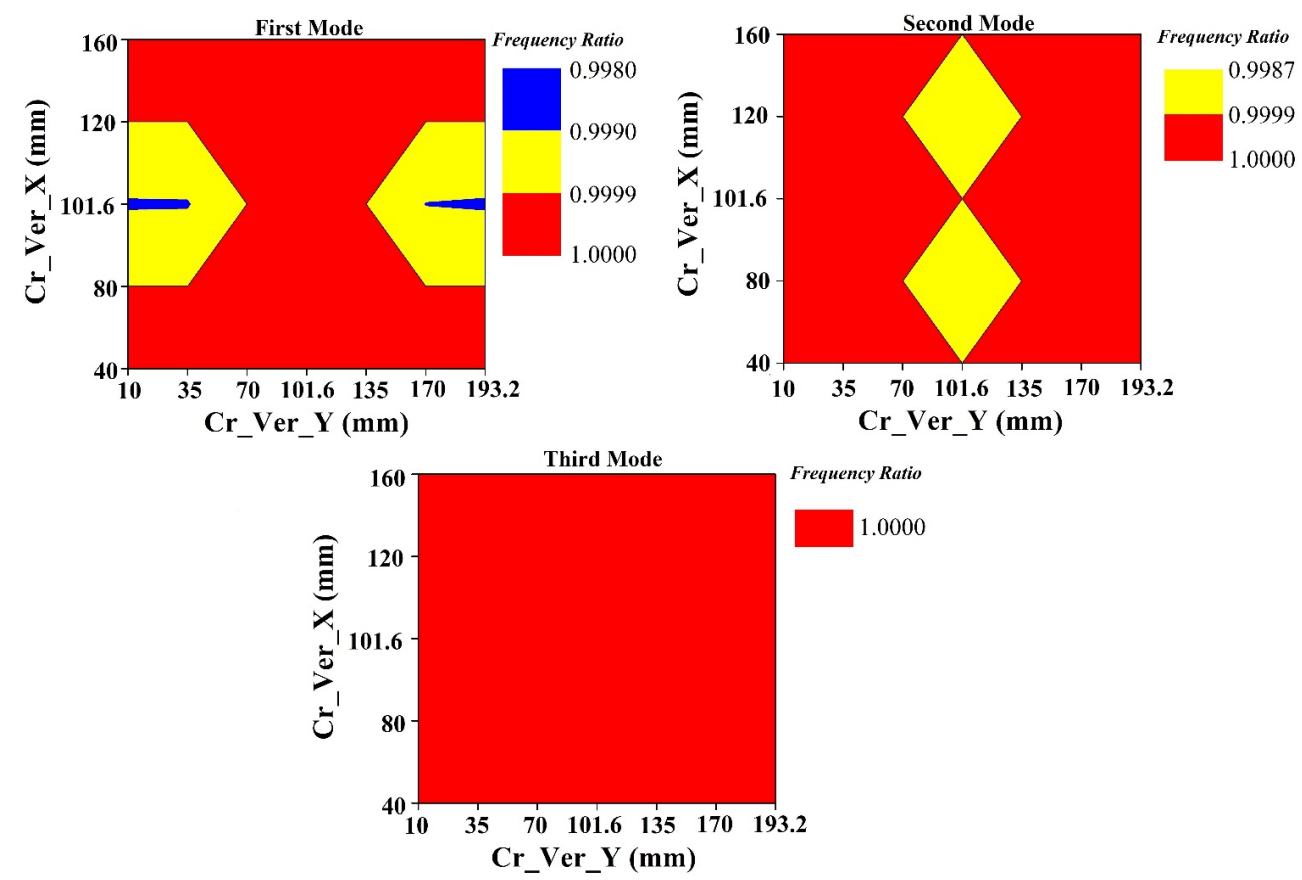

Figure 13 The first three frequency ratios ( $\omega_{\text {cracked }} / \omega_{\text {healthy }}$ ) of the stiffened plates fixed from stiffened edges having a vertical crack at different locations

It is seen from Figure 13 that the vertical crack has a negligible effect on the first two natural frequencies, while its effect diminishes for the third natural frequency. The vertical crack has affected the natural frequencies up to $0.02 \%$ when they are located on or close to the stiffener. Although there is no significant impact on the natural frequencies caused by the vertical crack, even a small impact can show meaningful results in inverse engineering problems such as damage detection and/or localization. The effect of the crack location seems to be symmetric around the $x$ - and $y$-axis of the structure. Although the presence of the crack does not change the first three mode shapes, it affects the displacement regions of the first mode shape of the structure. Therefore, it can be concluded that the vertical crack has affected the structure's stiffness components related to the first natural frequencies, while its effect reduces for those related to the second and third natural frequencies. As seen in Figure 14, a crack on the stiffener narrows the maximum displacement region towards where the crack occurs. Nevertheless, this effect fades as the crack moves towards the center of the stiffened plate.

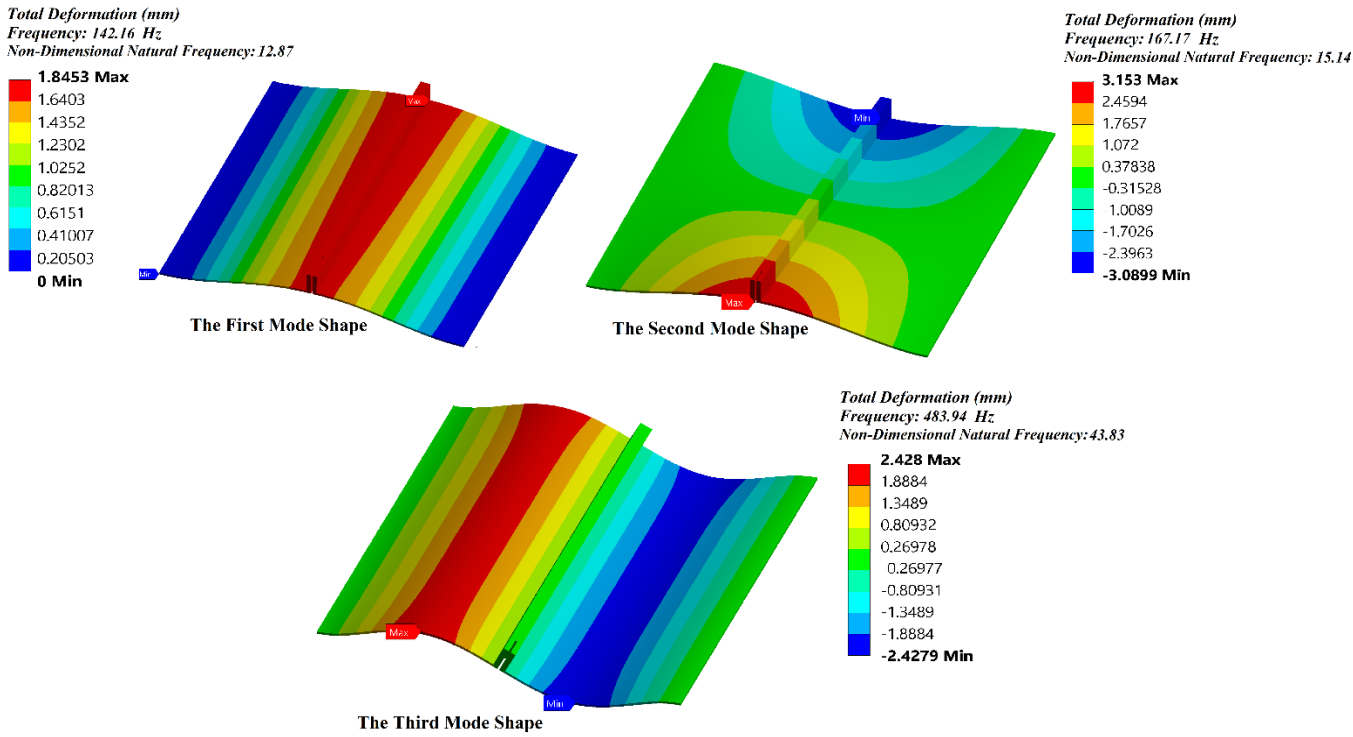

Figure 14 The first mode shape of the stiffened plates fixed from non-stiffened edges and having a vertical crack located at the stiffener end 
Figure 15 shows the changes in the first three natural frequencies in terms of the frequency ratio, $\omega_{\text {cracked }} / \omega_{\text {healthy }}$ for the stiffened plates fixed from the non-stiffened edges and having vertical plate crack in the locations indicated as Cr_Vert_X and Cr_Vert_Y (see Figure 1). It is seen from Figure 15 that vertical cracks slightly affect the first three natural frequencies of stiffened plates under fixed from non-stiffened edges boundary condition. The highest effect has been observed for the cracked structure whose crack located around the stiffened edge reduces the second natural frequency by $1.2 \%$ when compared with that of the healthy structure. The first and third natural frequencies have been negligibly affected by vertical cracks. On the other hand, it is seen from Figure 15 that the cracks located at the stiffened edges have a similar impact pattern on the second and third natural frequencies of the structure fixed from non-stiffened edges. This is because the vertical crack does not only exist in the bending regions but also penetrates these regions. Such a penetration also forces the crack to bend, which lowers the integrity of the structure. Hence, this can result in additional drops in the natural frequencies. On the other hand, the vertical cracks have been directed in parallel with the bending regions of the first and the third mode shapes. Considering Figures 15 and 5 , it can be interpreted that since those cracks have not penetrated any bending regions of those mode shapes, their impact on the corresponding natural frequencies is almost negligible. Therefore, it can be concluded that the cracks that occur along the bending regions slightly, but not negligibly affect the natural frequencies. The effect of the crack on those frequencies is symmetrical in the $x$ - and $y$-axis of the structure in accordance with the location of the vertical crack. The highest effect takes place as the crack occurs along the free stiffened edges. Unlike other boundary conditions - crack direction cases, the vertical crack does not cause any changes in the mode shapes of the structure. Therefore, the mode shapes that occurred in the presence of the crack are the same as those of healthy structure.
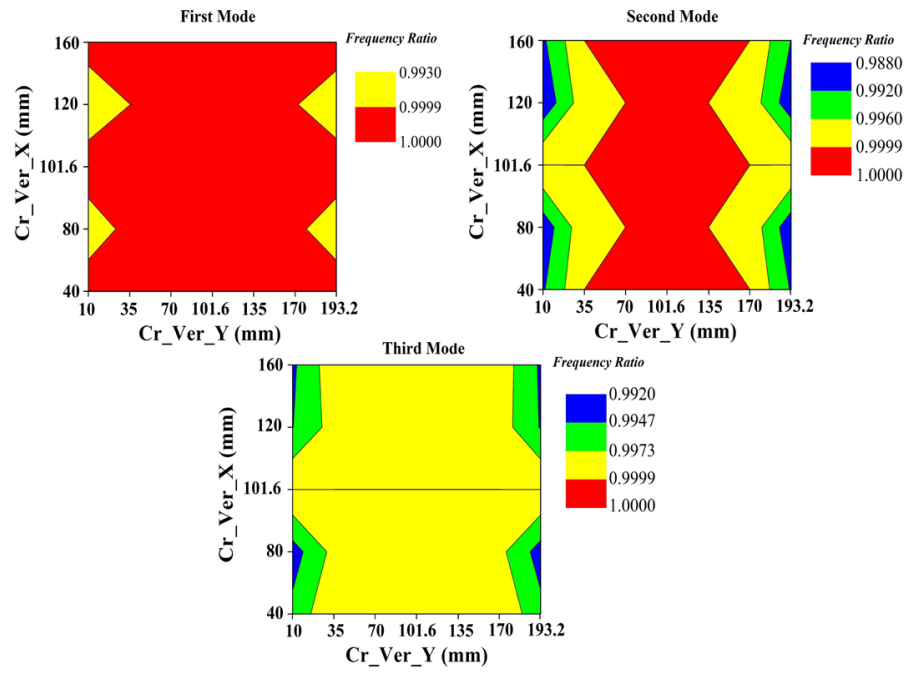

Figure 15 The first three frequency ratios ( $\left.\omega_{\text {cracked }} / \omega_{\text {healthy }}\right)$ of the stiffened plates fixed from non-stiffened edges having a vertical crack at different locations
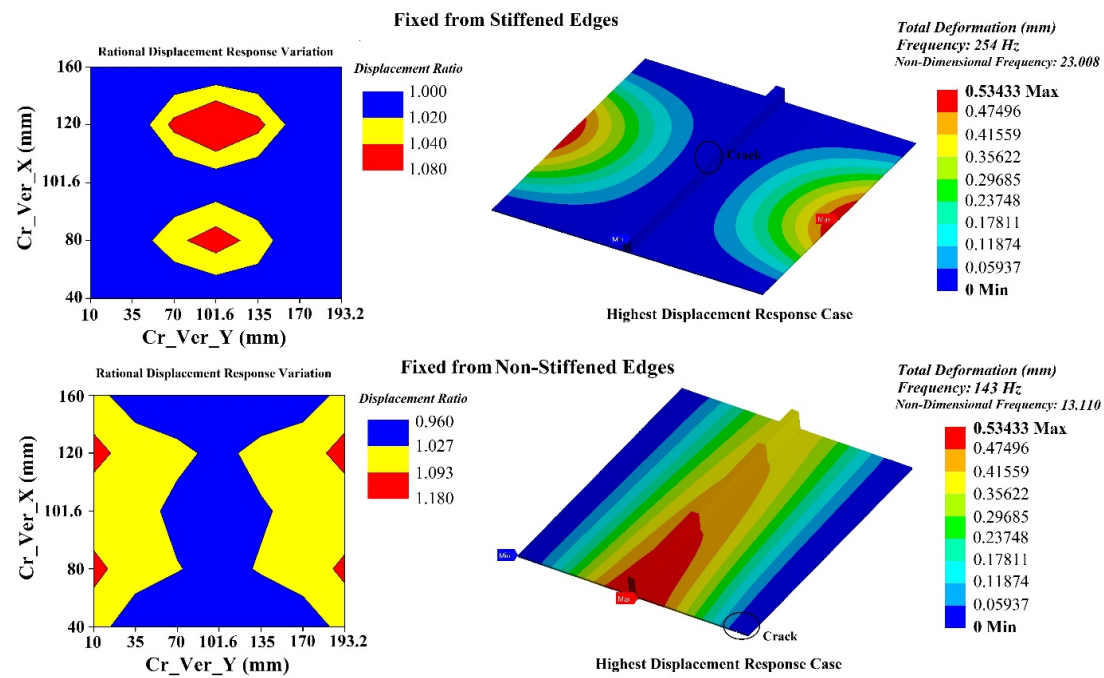

Figure 16 The displacement response ratios $\left(\delta_{\text {cracked }} / \delta_{\text {healthy }}\right)$ and highest response cases of the stiffened plates under fixed from stiffened edges having a vertical crack 
Figure 16 shows the displacement response ratio $\left(\delta_{\text {cracked }} / \delta_{\text {healthy }}\right)$ and the highest response distribution map obtained for stiffened plate structures fixed from stiffened edges and fixed from non-stiffened edges with a vertical plate crack. It is seen from Figure 16 that the displacement response varies symmetrically in the $x$ - and $y$-axis of the stiffened plate structure, in accordance with the vertical crack location. The highest response for the structure fixed from the stiffened edges is observed when a crack occurs at the middle region of the plate (around the stiffener). Therefore, the crack occurrence in this region increases the maximum displacement response of the structure by $8 \%$ when compared with that of the healthy structure. On the other hand, for the structure fixed from non-stiffened edges, the maximum displacement response is seen when the crack occurs at the free edges of the structure. The increment of the maximum displacement response is about $18 \%$ when compared with the maximum displacement response of the healthy structure. The displacement distribution of the vertically cracked structure fixed from stiffened edges is the same as the second mode of the healthy structure under the same boundary condition since the crack has slightly reduced the stiffness of the structure. On the other hand, the displacement distribution of the vertically cracked structure under fixed from nonstiffened edges is slightly different from that of the first mode of the healthy structure. As seen from Figure 16, the maximum displacement region has been narrowed to the crack location. Therefore, it can be concluded that the crack occurrence on the ends of the stiffener resulted in such a decrement in the stiffness of the structure the maximum displacement region of the structure shows up around the vertical crack. The crack occurrence has not considerably changed the displacement variation of the cracked structure under harmonic load. Noting that the maximum displacement response takes place at the second mode for the structure fixed from its stiffened edges and at the first mode for the structure fixed from its non-stiffened edges, the displacement variations are similar to their corresponding mode shapes. Therefore, a vertical or horizontal crack can only impact the maximum displacement response of the stiffened structure by lowering the structural integrity.

On the other hand, for the structure fixed from non-stiffened edges, as the crack moves from one end of the stiffener to the other, the displacement distribution fluctuates between the first mode shape, shown in Figure 6, and the highest displacement case, shown in Figure 16.

Figure 17 shows the displacement response diagram (Ramesha et al., 2015) of the stiffened plate structures under fixed from stiffened edges and fixed from non-stiffened edges conditions and having a vertically plate crack in different locations.
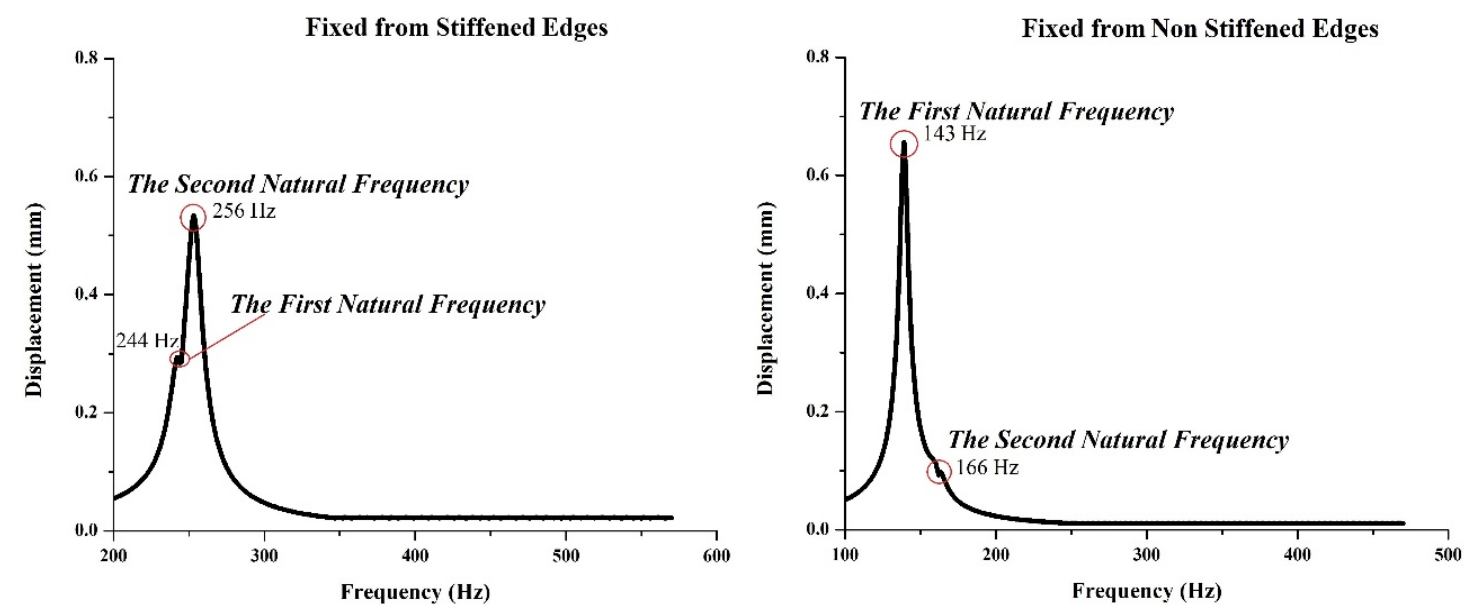

Figure 17 The critical frequency-displacement response diagram of stiffened plates under two different boundary conditions and having a vertical crack

It is seen from Figure 17 that the highest response of the vertically cracked structure fixed from stiffened edges occurs around the second mode, while it takes place around the first mode for the vertically cracked structure fixed from stiffened edges. Similar to the effect of the horizontal crack, the vertical crack also causes a noteworthy peak around the first frequency of the structure fixed from stiffened edges. On the other hand, unlike the horizontal crack, the vertical crack causes a considerable peak around the second frequency of the structure fixed from non-stiffened edges.

It is concluded that the horizontal and vertical plate cracks with a length of $20.38 \mathrm{~mm}$ affect the natural frequencies and the harmonic response of the stiffened structures under fixed from stiffened edges and fixed from non-stiffened edges boundary conditions. The considerable changes occur in certain crack locations such as free edges, the center of 
the plate, or along the stiffener. Such cracks, whose length is larger than the width of the stiffener, have the potential to not only change the natural frequencies of a stiffened structure but also significantly impact the displacement response of such structures under harmonic loading. The impact of these cracks may increase if they are located in the regions where they intersect both the plate and the stiffener. This is because the cracks lengthier than the width of the stiffener may adversely affect the structural integrity more than the smaller cracks.

According to the free vibration analysis, it is seen that the vertical and horizontal stiffener cracks do not affect the first three natural frequencies and the corresponding mode shapes regardless of the boundary condition of the structure. On the other hand, the displacement response of the structure is slightly affected depending on the direction of the crack and the boundary condition of the structure. Figure 18 shows the effect of the vertical and horizontal stiffener cracks on the displacement response considering the ratio, $\delta_{\text {cracked }} / \delta_{\text {healthy }}$.
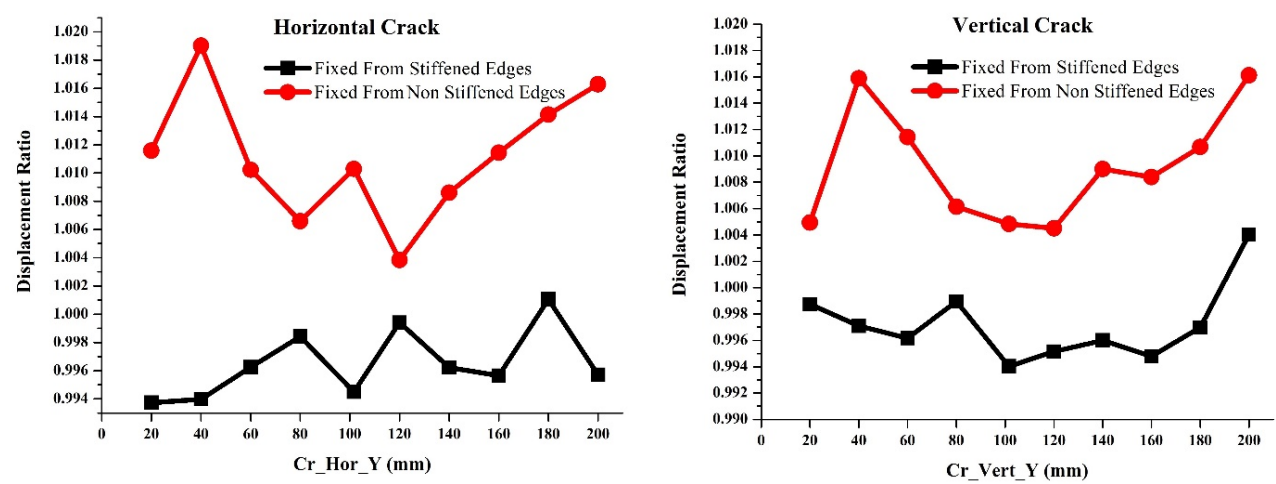

Figure 18 The displacement response variation of stiffened plates under two boundary conditions and having a horizontal or vertical crack occurred on the stiffener in different locations

As seen from Figure 18, the stiffener crack is slightly affected the displacement response of stiffened plates under different boundary conditions. The impact of the stiffener crack of the structure fixed from non-stiffened edges is slightly higher than that of fixed from stiffened edges. The highest impact has been observed for the horizontally cracked structure fixed from nonstiffened edges. The maximum displacement value of the structure, which has a crack at the near-end of the stiffener is about $2 \%$ higher than the healthy structure under fixed from non-stiffened edges boundary condition. The horizontal and vertical cracks that occurred along the stiffener of the structure under fixed from stiffened boundary condition have the slightest impact on the displacement response of the structure. This is because the boundary condtion also constrains the stiffener, and therefore, no bending regions occurred along the stiffener for the second natural frequency, where maximum displacement response occurs. Since the crack does not intersect or take place in any bending regions, its effect on the stiffness of the structure becomes small. Hence, the impact of the horizontal and vertical cracks for the structure under fixed from stiffened edges boundary condition does not even reach $1 \%$.

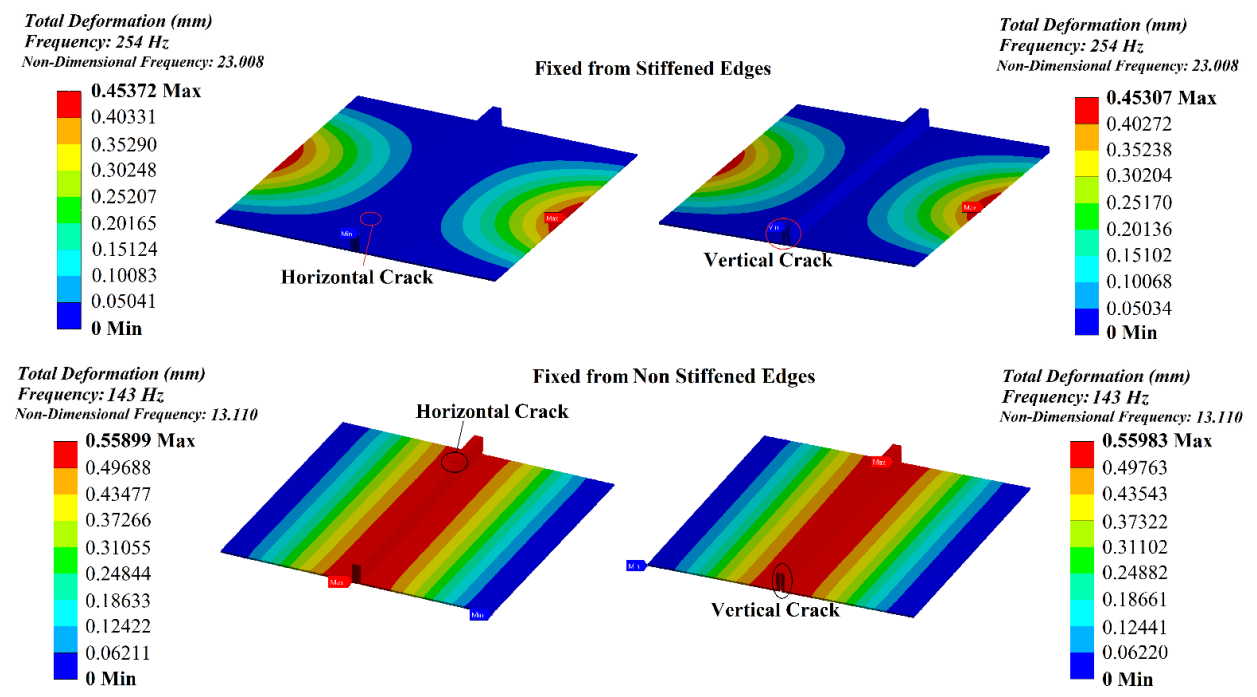

Figure 19 The displacement response map of horizontal and vertical cracks located in different points on the stiffener considering two boundary conditions 
Figure 19 shows the illustrations of the effect of the horizontal and vertical stiffener crack located in different places on the stiffener. It is seen from Figure 19 that the stiffener crack does not considerably affect the displacement response distribution of the stiffened plate structure regardless of the crack direction and boundary conditions. The reason for such a small impact on the displacement responses is because of the size of the stiffener crack ( $5 \mathrm{~mm}$ ) is insufficient to provide a considerable impact on the stiffness of the structure. Therefore, the displacement response distribution of the stiffened structure is solely dependent on its boundary condition if it contains a stiffener crack. It can be concluded that the length of the crack may affect the harmonic response only if it is long enough to disrupt the structural integrity. Figure 20 shows the frequency-displacement response diagram of two crack cases and boundary conditions of stiffened plates.
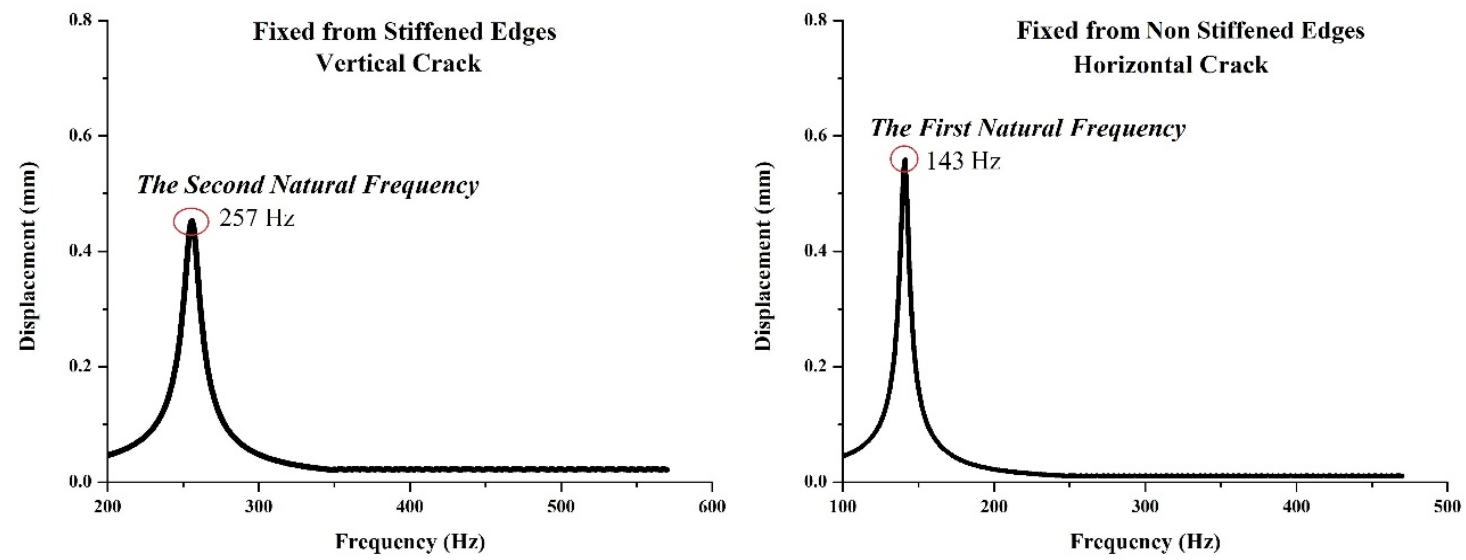

Figure $\mathbf{2 0}$ The frequency - displacement response diagrams of stiffened plates considering two crack cases and boundary conditions

It is seen from Figure 20 that the maximum response takes place around the second frequency of the cracked stiffened plate structures under fixed from stiffened edges boundary condition. On the other hand, the maximum response occurs around the fundamental frequency of the cracked stiffened plate under fixed from non-stiffened edges boundary conditions. Apart from the plate cracks, there are no additional peaks seen in the displacement response diagrams. Therefore, it can be concluded that lengthier cracks can cause additional peaks that should be taken into consideration since they may endanger the structure's health.

\section{CONCLUSIONS}

This study presents the effects of crack direction, location, and length on the free vibration and harmonic response of the stiffened plates under fixed from stiffened edges and fixed from non-stiffened edges boundary conditions. According to the numerical results given in the previous section, the following conclusions have been drawn.

- It is concluded that the horizontal plate cracks on the stiffened structure, fixed from non-stiffened edges, it is seen from the results that a horizontal crack located at the center of the structure has affected the third natural frequency of the structure by $60 \%$.

- The harmonic response analysis results indicate that the horizontal plate cracks increase the displacement responses of the structure fixed from stiffened structures by $18 \%$ as they are located along the free edges.

- The displacement response of the structure fixed from non-stiffened edges is increased by $18 \%$ as the vertical plate cracks occur at the locations close to the corners of the structures.

- $\quad$ The vertical plate cracks located at the center and on the stiffener cause an increment of $8 \%$ in the displacement response of the stiffened plate structures fixed from stiffened edges.

- $\quad$ Stiffener cracks do not significantly impact the displacement response or the natural frequencies of the structures no matter what the constraint is.

- The impact of the crack on the natural frequency of the structure becomes more significant if it occurs in locations where high slope values of bending regions are observed. In addition, the effect of the crack on the natural frequencies also increases if the crack is penetrating both the width and the thickness of the stiffener. 
- According to the numerical results, if a crack penetrates the bending regions, its impact on the displacement response and the natural frequency of the structure increases.

- In addition to the aspects of the crack, the structural thickness may also play an important role in the displacement response and natural frequencies of the structure in the presence of the crack since it directly affects the stiffness of the structure.

- The effect of the plate and stiffener cracks on the harmonic response varies symmetrically in accordance with the crack locations. Therefore, the crack constitutes similar changes in the natural frequency and the displacement responses when it is located at opposing free or fixed edges.

- The displacement response distributions caused by the harmonic load are in a similar pattern with the corresponding mode shapes unless the crack size, location, and direction do not affect the stiffness of the structure considerably. When such an impact takes place, the crack causes a change in the mode shape of the corresponding natural frequency where the maximum displacement response takes place. Besides, the crack can also impact the size of the displacement regions of the corresponding mode shape.

- The numerical results of this study indicate that the natural frequencies and harmonic response of a damaged structure can be used for inverse engineering problems, such as crack detection, identification of material properties, etc.

Author's Contribuitions: Conceptualization, O Das and C Gonenli, Data curation, O Das, Methodology, O Das, Investigation, O Das and C Gonenli, Resources, O Das, Visualization, O Das, Writing - original draft, O Das, Writing review \& editing, $O$ Das and C Gonenli.

Editor: Marco L. Bittencourt

\section{References}

Abed, Z: A. K., and Majeed, W. I., (2020). Effect of boundary conditions on harmonic response of laminated plates. Composite Materials and Engineering. 2(2): 125-140.

Alavi, S. H., and Eipakchi, H., (2021). An analytical approach for dynamic response of viscoelastic annular sector plates. Mechanics of Advanced Materials and Structures.

Al-Zubaidi, D. H. J., Al-Waily, M., and Hussein, E. Q., (2020). Analytical investigation of crack depth and position effect onto beam force vibration response with various harmonic frequency influence. Internatıonal Journal of Energy and Environment. 11: 1-28.

Babazadeh, A., and Khedmati, M. R., (2018). Ultimate strength of cracked ship structural elements and systems: A review. Engineering Failure Analysis. 89: 242-257.

Berger, M. J. and Oliger, J. (1983). Adaptive mesh refinement for hyperbolic partial differential equations. Journal of Computational Physics. 53(3): 484-512.

Cruceanu, I. C., and Sorohan, S., (2020). Determination of the harmonic response of a railway wheelset using the finite element analysis method. Procedia Manufacturing. 46: 173-179.

Damnjanović, E., Marjanović, M., and Nefovska-Danilović, M., (2017). Free vibration analysis of stiffened and cracked laminated composite plate assemblies using shear-deformable dynamic stiffness elements. Composite Structures.180: 723-740.

Gonenli, C., and Das, O., (2021). Effect of crack location on buckling and dynamic stability in plate frame structures. Journal of the Brazilian Society of Mechanical Sciences and Engineering. 43: 311.

Gonenli, C., Ozturk, H., and Das, O., (2021). Effect of crack on free vibration of a pre-stressed curved plate. Proceedings of the Institution of Mechanical Engineers, Part C: Journal of Mechanical Engineering Science.

Hamedani, S. H., Khedmati, M. R., and Azkat, S. (2012). Vibration analysis of stiffened plates using Finite Element Method. Latin American Journal of Solids and Structures. 9(2012): 1-20.

Hoai, N. V., Doan, D. H., Khoa, N. M., Do, T. V., and Tran, H. T., (2019). Phase-field buckling analysis of cracked stiffened functionally graded plates. Composite Structures. 217: 50-59. 
Hongwei, G., Hong, Z., and Xiaoying, Z., (2019). Numerical manifold method for vibration analysis of Kirchhoff's plates of arbitrary geometry. Applied Mathematical Modelling. 66: 695-727.

Isanaka, B. R., Akbar, M. A., Mishra, B. P., and Kushvaha, V., (2020). Free vibration analysis of thin plates: Bare versus Stiffened. Engineering Research Express. 2: 015014.

Kiral, Z. (2014). Harmonic response analysis of symmetric laminated composite beams with different boundary conditions. Science and Engineering of Composite Materials. 21(4): 559-569.

Koko, T. S., and Olson, M. D., (1992). Vibration analysis of stiffened plates by super elements. Journal of Sound and Vibration. 158(1): 149-167.

Kumar, S. S., Clement H. A., and Karthik, R., (2017). Mixed mode fracture analysis of multiple cracks in flat and curved stiffened panels of aircraft fuselage structures. Archive of Applied Mechanics. 87: 1815-1828.

Minh, P.P., Do, T. V., Duc, D. H., and Duc, D. N., (2018). The stability of cracked rectangular plate with variable thickness using phase field method. Thin-Walled Structures. 129: 157-165.

Olson, M. D., and Hazel, C. R., (1977). Vibration studies on some integral rib-stiffened plates. Journal of Sound and Vibration. 50(1): 43-61.

Ozdemir, M., Sadamoto, S., Tanaka, S., Okazawa, S., Yu, T. T., and Bui, T. Q., (2018) Application of 6-DOFs meshfree modeling to linear buckling analysis of stiffened plates with curvilinear surfaces. Acta Mechanica. 229: 4995-5012.

Petyt, M., (2010). Introduction to Finite Element Vibration Analysis, Cambridge Press (New York).

Ramesha, C. M., Abhijith, K. G., Singh, A., Raj, A., and Naik, C. S., (2015). Modal analysis and harmonic response analysis of a crankshaft. International Journal of Emerging Technology and Advanced Engineering. 5(6): 323-327.

Singh, D. K., and Pal, P., (2021). Forced Vibration Analysis of Stiffened Lock Gate Structure. Journal of Sound and Vibration. 510: 116278 .

Xue, J., Wang, Y., and Chen, L., (2020). Nonlinear vibration of cracked rectangular Mindlin plate with in-plane preload. Journal of Sound and Vibration. 481: 115437.

Yu, Y., Zhang, S., Li, H., Wang, X., and Tiang, Y., (2017). Modal and harmonic response analysis of key components of ditch device based on ANSYS. Procedia Engineering. 174: 956-964.

Zeng, J., Chen, K., Ma, H., Duan, T., and Wen, B., (2019). Vibration response analysis of a cracked rotating compressor blade during run-up process. Mechanical Systems and Signal Processing. 118: 568-583.

Zhang, C., Jin, G., Ye, T., and Zhang, Y., (2018). Harmonic response analysis of coupled plate structures using the dynamic stiffness method. Thin-Walled Structures. 127: 402-415. 


\section{APPENDIX 1}

The free vibration analysis of the cracked stiffened plates has been obtained considering the equation of motion given in equation (1) (Petyt, 2010)

$$
[M]\{\delta\}+[K]\{\delta\}=0
$$

The stiffness and mass matrices have been evaluated considering the potential and kinetic energy equations. The potential energy of the plate depending on the stiffness matrix is given in equation (2) (Petyt, 2010).

$U=\frac{1}{2}\{\delta\}^{T}[K]\{\delta\}$

The kinetic energy of the plate depending on the mass matrix is given in equation (3) (Petyt, 2010).

$T=\frac{1}{2}\{\dot{\delta}\}^{T}[m]\{\dot{\delta}\}$

The displacement vector $\{\delta\}$ is presented in equation (4) as

$\{\delta\}=\left[w \theta_{x} \theta_{y} u v r \quad \theta_{z}\right]$

The details of the corresponding mathematical expressions can be found in various publications (Petyt, 2010; Hamedani et al, 2012). The free vibration analysis problem can be solved by as an eigenvalue problem given in equation (5).

$[K]-{ }^{2}[M]=0$

In the presence of damping and force, the equation of motion becomes as given in equation (6). (Petyt, 2010)

$[M]\{\ddot{\delta}\}+[\mathrm{C}]\{\dot{\delta}\}+[K]\{\delta\}=\{\mathrm{F}\}$

The representation of the harmonic load in complex form is given in equation (7) as (Petyt, 2010)

$\{\mathrm{F}\}=\left\{\mathrm{F}_{\max }\right\} \mathrm{e}^{\mathrm{j} \phi} e^{j \omega t}$

The response of the structure of the applied harmonic load is given in equation (8) (Petyt, 2010).

$\{\delta\}=\left\{\delta_{\max }\right\} \mathrm{e}^{\mathrm{j} \psi} e^{j \omega t}$

The harmonic response analysis problem can be solved by using equation (9), which is obtained by substituting equations (7) and (8) into equation (6).

$\left(-[M] \omega^{2}+\mathrm{j}[\mathrm{C}] \omega+[K]\right)\{\delta\}=\{\mathrm{F}\}$ 